\title{
Ideological diversity, hostility, and discrimination in philosophy
}

\section{Uwe Peters, Nathan Honeycutt, Andreas De Block \& Lee Jussim}

To cite this article: Uwe Peters, Nathan Honeycutt, Andreas De Block \& Lee Jussim (2020) Ideological diversity, hostility, and discrimination in philosophy, Philosophical Psychology, 33:4, 511-548, DOI: 10.1080/09515089.2020.1743257

To link to this article: https://doi.org/10.1080/09515089.2020.1743257

\section{0.}

Submit your article to this journal $\sqsubset$

Џll Article views: 94

Q View related articles ๘

View Crossmark data $₫$ 


\title{
Ideological diversity, hostility, and discrimination in philosophy
}

\author{
Uwe Peters $^{\mathrm{a}, \mathrm{b}}$, Nathan Honeycutt $\mathbb{D}^{c}$, Andreas De Block ${ }^{\mathrm{d}}$ and Lee Jussim ${ }^{c}$
}

aDepartment of Philosophy, University of Southern Denmark, Denmark; bepartment of Psychology, King's College London, UK; 'Department of Psychology, Rutgers University, New Brunswick, United States; ${ }^{\mathrm{d} C e n t r e}$ for Logic and Philosophy of Science, Leuven, Belgium

\begin{abstract}
Members of the field of philosophy have, just as other people, political convictions or, as psychologists call them, ideologies. How are different ideologies distributed and perceived in the field? Using the familiar distinction between the political left and right, we surveyed an international sample of 794 subjects in philosophy. We found that survey participants clearly leaned left (75\%), while right-leaning individuals (14\%) and moderates (11\%) were underrepresented. Moreover, and strikingly, across the political spectrum from very left-leaning individuals and moderates to very rightleaning individuals, participants reported experiencing ideological hostility in the field, occasionally even from those on their own side of the political spectrum. Finally, while about half of the subjects believed that discrimination against leftor right-leaning individuals in the field is not justified, a significant minority displayed an explicit willingness to discriminate against colleagues with the opposite ideology. Our findings are both surprising and important because a commitment to tolerance and equality is widespread in philosophy, and there is reason to think that ideological similarity, hostility, and discrimination undermine reliable belief formation in many areas of the discipline.
\end{abstract}

\section{ARTICLE HISTORY}

Received 10 January 2019

Accepted 3 July 2019

\section{KEYWORDS}

Ideological bias; diversity; demographics

\section{Introduction}

"When I look upon my own discipline, the discipline of philosophy,

I find egregious effects of ideology."

(Stanley, 2015, p. xvi)

One of the most interesting and salient properties that individuate subjects and groups is their political conviction, or ideology, that is, their being, for instance, liberal, conservative, socialist, feminist, anarchist, and so on (Jost et al., 2009). Determining whether subjects "are engines of change or preservers of the status quo," and so identifying their ideology, has in fact

CONTACT Uwe Peters u.peters@ucl.ac.uk D Department of Philosophy, University of Southern Denmark (c) 2020 Informa UK Limited, trading as Taylor \& Francis Group 
been found to be one of the "fundamental dimensions on which people spontaneously distinguish social groups" (Koch et al., 2016, p. 702).

In the wake of recent dramatic changes in politics throughout the world, such as Trump's US presidency, Brexit, and the rise of populist parties, social identity is becoming increasingly more the target and source of bias and hostility between people (Iyengar \& Massey, 2019; Maher et al., 2018). Studies found, for instance, that bias and hostility against ideological opponents are now more pronounced than those directed at gender, race, religious, linguistic, or regional out-groups (Iyengar \& Westwood, 2015; Westwood et al., 2018).

Importantly, ideological bias and hostility might also leak into academic disciplines and contribute to a decrease in viewpoint diversity within them, leading to detrimental epistemic outcomes (Longino, 2002, p. 132; Jussim et al., 2018; Peters, 2019). Indeed, studies already found that certain ideological groups are faced with overt or covert biases and discrimination in, for instance, the social sciences (Honeycutt \& Freberg, 2017; Inbar \& Lammers, 2012; Yancey, 2011). ${ }^{2}$

What do we know about the representation of different political viewpoints and the ideological biases against them among members of the field of philosophy (henceforth "philosophers") ${ }^{3}$ in particular? While there has been much discussion in philosophy about diversity and bias against various underrepresented groups in the field (Allen-Hermanson, 2017a; Botts et al., 2014; Brownstein \& Saul, 2016; Kings, 2019), there is no systematic and inclusive study pertaining to the distribution of and possible bias against ideologies in the field. As Schwitzgebel and Hassoun (2018) note, "political viewpoint" is one of the most "under-studied dimensions of diversity [in philosophy]."

This gap in the research is unfortunate, for there are philosophers with different ideologies ranging from the political left to the right who claim their political viewpoints are underrepresented and subject to "ideological bias" and discrimination in the field (Haslanger, 2008, p. 216; Saul, 2015; Kings, 2019, pp. 214f, 225f; Case, 2015; Sesardic, 2016). These claims warrant a careful empirical assessment. After all, philosophers and philosophical institutions often emphasize the "imperative of philosophizing to strive for an open community into which all are welcome," explicitly condemn discrimination based on "political convictions" as "unethical," 6 and define philosophy as "unbridled criticism" (Priest, 2006, p. 207). Such statements of openness, tolerance, and free criticism are clearly in tension with ideological biases and discrimination. They beg the question as to whether the field of philosophy is indeed also, just as, for instance, the social sciences (Honeycutt \& Freberg, 2017; Yancey, 2011), affected by these ideology-related phenomena. 
In fact, the question is arguably especially important when it comes to the field of philosophy. This is because while scientific claims can usually be experimentally tested, philosophical claims frequently cannot or simply are not. For instance, in ethics, political philosophy, philosophy of science, or philosophy of religion, claims are often value-laden and admit no straightforward empirical check: whether abortion is murder, economic equality just, verificationism tenable, or the theodicy problem disproof of God cannot be settled experimentally. Granted, some philosophical research can be experimentally assessed (Knobe \& Nichols, 2017). But much is accepted on the basis of intuitions and "subtle appeals to plausibility," which are particularly susceptible to influences of values and biases (Kornblith, 1999, p. 185). To protect themselves from blind spots and errors in their reasoning, philosophers thus rely much moreon social criticism than scientists do. Since ideological biases and a lack of ideological diversity reduce the scope of social criticism, they threaten the reliability of philosophical belief-formation (Peters, 2019).

We, a politically diverse team of philosophers and social psychologists, therefore conducted a systematic international survey pertaining to ideological diversity and bias in philosophy. Before turning to the details and results of the survey, we will provide a brief overview of the existing work on the issue.

First, however, a terminological clarification: while the terms 'bias,' 'hostility,' and 'discrimination' have negative moral connotations related to the idea of unfairness, we shall use these expressions more neutrally in that we grant that some ideological biases, hostility, and discrimination might be epistemically and/or ethically beneficial and justified (Antony, 2016; Fantl, 2018 , p. 177f). Whether or not that is so needs to be assessed on a case-bycase basis. ${ }^{7}$ Our focus here is primarily on exploring the reality of ideological biases, hostility, and discrimination in philosophy. We do, however, believe and briefly argue below, in Section 7, that these phenomena are also often both epistemically and ethically costly enough to consider counteracting them.

\section{Previous research}

Studies that provide insights into the distribution of and possible bias against ideologies in philosophy are rare. Moreover, most of the existing ones were conducted only with US samples, and they focus mainly on liberals and conservatives, or Democrats and Republicans. 


\subsection{Data on the distribution of ideologies in philosophy}

There are three different kinds of relevant studies. Rothman and Lichter (2009) report findings from the North American Academic Study Survey (NAASS), noting that among philosophy professors $(N=26), 79 \%$ selfidentified as liberals and $4 \%$ as conservatives. Relying instead on public voting records of professors in a number of US states, Schwitzgebel (2008) found that, among philosophers $(N=375), 87.2 \%$ were Democrats, $7.7 \%$ Republicans, $2.7 \%$ Greens, $1.3 \%$ Independents, $0.8 \%$ Libertarians, and $0.3 \%$ Peace \& Freedom. Similarly, Klein and Stern (2009) report three US voter registration studies finding a Democrat to Republican ratio of 5:1, 9:1, 24:1 among philosophers. Other relevant data come from Bourget and Chalmers (2014), who sent a survey to 1,972 philosophy faculty members at 99 institutions in Anglophone countries, questioning them about 30 philosophical topics. One was related to politics, asking respondents whether they favored egalitarianism, communitarianism, libertarianism, or another position not specified. From 931 respondents, 34.8\% favored egalitarianism, $14.3 \%$ communitarianism, $9.9 \%$ libertarianism, and $41.0 \%$ other, unspecified positions.

To our knowledge, these three kinds of studies are the only ones that are currently available on the distribution of ideologies in philosophy. Even less is known about the existence and frequency of ideological bias in the field.

\subsection{Data on ideological bias in philosophy}

Two surveys provide relevant data. Using the liberal-conservative distinction, Honeycutt and Freberg (2017) polled 618 academics from various disciplines, including philosophy, across four Californian universities. They found an overt bias against conservatives among liberals as well as a bias against liberals among conservatives in, for instance, the assessment of grant applications, the review of papers, and hiring decisions. Their data analysis does not allow for specific conclusions about the field of philosophy, however.

Yancey (2011) conducted a study that does. He surveyed 160 US philosophers on whether being a Democrat or a Republican damages acceptance of job applicants. Specifically, participants had to rate their own attitude on a 7-point scale in which ' 1 ' indicated that the characteristic at issue would "greatly damage" the participant's own "support to hire" an applicant, and ' 7 ' indicated that the characteristic would "greatly enhance" it (Yancey, 2011, p. 220). ${ }^{8}$ Yancey found a mean score of 4.248 for Democrats and a mean score of 3.699 for Republicans (Yancey, 2011, pp. 117, 188). Since scoring below the 4.0 midpoint indicated that participants were overall 
more likely to reject than to accept applicants solely on the basis of their ideology, the data suggest the presence of a bias against Republicans in the sample.

As far as we know, these two studies provide all of the existing professionally collected and published quantitative data on ideological bias, hostility, and discrimination in philosophy. There are other relevant findings, however.

\subsection{Informally gathered data and anecdotes}

Weinberg (2016) used his website Daily Nous to ask people working in philosophy "which ideas are students protected from?" and "which are faculty fearful to defend?" ${ }^{2}$ He reports that out of 132 responses, "several of the more popular answers on the list" of "ideas faculty are too scared to defend" were "critiques of feminism, critiques of homosexuality, critiques of race- and gender-based affirmative action, importance of racial differences in IQ and behavior for social programs, [and] critiques of transgender "ideology." 10 These ideas are often considered politically conservative.

There is also anecdotal evidence of ideological bias. ${ }^{11}$ For instance, conservative philosophers have reported feeling fearful to express their viewpoints in the field (Shields \& Dunn, 2016, pp. 104, 123), and claimed that they are often ridiculed (Sesardic, 2016, p. 200) or told that their "ideas and sentiments are reactionary, prejudiced, sexist, or racist" (Scruton, 2014, p. 12). Similarly, left-leaning philosophers have held that there is, for instance, not only an anti-female, but also an "antifeminist bias in philosophy" (Haslanger, 2008, p. 216; see also Saul, 2013, 2015; Kings, 2019). The matter clearly calls for more research.

\section{The survey}

To assess the distribution of and possible bias against political viewpoints in philosophy, we surveyed an international sample of philosophers, contacting them per e-mail via the "Liverpool List," also known as "PHILOS-L." PHILOS-L is the "largest philosophy email list in the world with currently 10,896 members in over 60 countries." 12 Given the international and diverse nature of the subjects on the list, the recruitment of our sample called for a particular conceptualization of participants' political identity.

\subsection{Key concepts}

There are different concepts that might be used to track the ideology of participants in a survey. In related studies in fields other than philosophy, researchers relied on respondents' self-identification in terms of the 
liberal-conservative distinction (Honeycutt \& Freberg, 2017; Inbar \& Lammers, 2012). The liberal-conservative distinction has, however, significantly different meanings internationally, and just like the DemocratRepublican distinction, it is less familiar in cross-national contexts (Carl, 2015; Goldfarb, 2010). Thus, we refrained from using it.

We reasoned instead that the more units (e.g., people) a comparison involves and the greater the range of settings in which they are found (e. g., countries), the more abstract the concepts employed in the comparison will need to be in order to be able to form interesting generalizations. Political scientists have noted that, largely because of this point, the wellknown political "left-right orientations, and the search for placements along a left-right dimension, have proved such an enduring element in comparative political analysis" (Mair, 2009, p. 207). And indeed, even thoughthere is no unanimously accepted definition of the political left versus the right, the left-right spectrum is internationally widely understood in the way depicted in Figure 1 (Heywood, 2015, p. 119).

While it remains a simplification of political reality, the left-right distinction is "ubiquitous [in politics and in] public opinion surveys all over the world, [and] self-placement on a left-right scale [...] consistently proves to be one of the best predictors of a person's political attitudes and behavior" (Noel \& Therien, 2008, p. 10). There is also an overlap internationally when it comes to key components of the meaning of the dichotomy (Bobbio, 1996; Lukes, 2003). Studies suggest that all "around the world [there is a] recurrent association between the left, egalitarianism, and state intervention [to regulate the economy]. By contrast, the right is invariably identified with market liberalization and lesser state intervention [in the economy]" (Rosas \& Ferreira, 2013, p. 9; Rockey, 2014; Cochrane, 2015). Relatedly, a 2018 study focusing on eight countries (Australia, Chile, Germany, Italy, Poland, Spain, UK, and the United States) found that despite the different national histories, left and right "still summarize and mediate the influence that personality features like basic values and core political values may exert on political choices," and they "refer to similar patterns of values and principles across political contexts," making the "left-right ideology [...] worthy of careful consideration [...] for scholars to address, predict, and compare political preferences across countries" (Caprara \& Vecchione, 2018, pp. 70, 79). Thus, we too decided to use self-identification on the left-right spectrum to track political viewpoints.

Notice that one might, for instance, be left-leaning on social issues in that one favors personal freedom, equality, social justice, and so on, but rightleaning on economic issues in that one favors economic freedom and accepts economic inequalities, competitive capitalism, and so on 


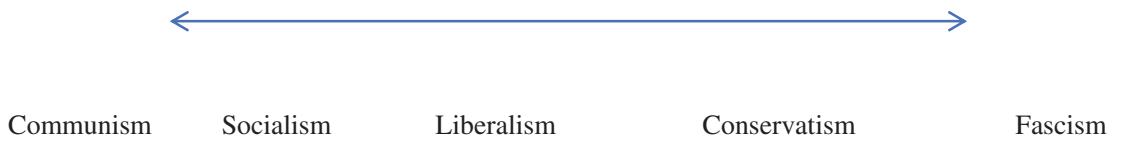

Figure 1. Linear left-right spectrum.

(Crawford et al., 2017, p. 385). The reverse might hold too. To capture these differences, we asked participants not only about their overall left or right self-identification but also about how they see themselves on the left-right spectrum when it comes to social and economic issues.

\subsection{Main questions and hypotheses}

The study was structured around three main questions: (1) How are left or right ideologies distributed in philosophy? (2) Is there a bias, hostility, or discrimination against left- or right-leaning individuals or viewpoints in the field? (3) If so, do members of the field take them to be justified? Corresponding to questions 1-3, and partly based on the results of related extant research on the "ideological conflict hypothesis" (Brandt et al., 2014), which posits that people with different ideologies dislike ideas that conflict with their own and aim to maintain their worldview via motivated information-processing against worldview-violating groups, we generated a set of hypotheses. They were pre-registered ${ }^{13}$ prior to data collection. Our main hypotheses ${ }^{14}$ were the following:

Hypothesis 1 (H1): Philosophers are predominantly left-leaning.

Hypothesis 2 (H2): The more left-leaning the participant, the less hostility they will report experiencing, and, correspondingly, the more right-leaning the participant, the more hostility they will report experiencing.

Hypothesis 3 (H3): Left-leaning and right-leaning individuals report similar willingness to discriminate against each other.

Hypothesis 4 (H4): There is a significant association between ideology and justification of discrimination against left- or right-leaning individuals, such that the more right-leaning participants will consider discrimination against the left to be more justified, and the more left-leaning participants will consider discrimination against the right to be more justified. 


\section{Method}

We used a survey instrument adapted from Honeycutt and Freberg (2017). It includes questions about hostility and discrimination against both leftleaning and right-leaning individuals and contents (i.e., arguments, claims, etc.). That is, the questions were "mirrored" for ideological opposites. ${ }^{15}$ The instrument, which was hosted on a secure Qualtrics site, is available online on an OSF platform (see the link below). ${ }^{16}$ All study material received prior approval by the Social and Societal Ethics Committee (SMEC) at KU Leuven and the Institutional Review Board at Rutgers University.

\subsection{Sample}

In June and July of 2018, 1069 participants were recruited from the PHILOS-L server. A total of 275 participants were excluded using prespecified data-exclusion criteria, ${ }^{17}$ resulting in a final sample of 794 participants (562 males, 213 females, 19 other/no response; age range: 18-85; average age: 37.1 ). Of these participants, 691 (87\%) were White, 29 multiracial, 24 Asian, 17 Hispanic or Latino(a), 17 Middle-Eastern or North African, 3 Black or African American, and 2 Native Hawaiian or other Pacific Islander. Eleven participants declined to state their ethnicity. Most participants resided in Europe (67.13\%; see Table 1). Overall, 38\% identified as graduate student, $28.6 \%$ as full, associate, or assistant professor, $14.4 \%$ as post-doctoral researcher, $6.7 \%$ as assistant lecturer or teaching assistant, and $5.2 \%$ as undergraduate student. Seven percent selected 'other.' As for philosophical traditions, $57.7 \%$ of the participants worked in analytic philosophy, $27.6 \%$ in continental philosophy, and $14.8 \%$ indicated 'other.' For their area of specialization (participants were able to select more than one), 36.9\% mentioned 'political philosophy,' $35.3 \%$ 'ethics,' $21.7 \%$ 'philosophy of science,' $21.4 \%$ 'history of philosophy,' $20.3 \%$ 'epistemology,' $18.4 \%$ 'metaphysics,' $17.5 \%$ 'philosophy of mind,' $13 \%$ 'phenomenology,' $7.8 \%$ 'aesthetics,' $7.7 \%$ 'philosophy of religion,' $6.9 \%$ 'logic,' and 16\% selected 'other.'

Table 1. Geographic region of participants.

\begin{tabular}{lcr}
\hline Region & Count & Percent \\
\hline Europe & 533 & $67.13 \%$ \\
North America & 175 & $22.04 \%$ \\
Middle East & 22 & $2.77 \%$ \\
Australia/New Zealand & 20 & $2.52 \%$ \\
South America & 10 & $1.26 \%$ \\
East Asia & 9 & $1.13 \%$ \\
Africa & 5 & $0.63 \%$ \\
No Response & 20 & $2.52 \%$ \\
\hline
\end{tabular}




\subsection{Measures}

We presented participants with different types of questions. The four main types were the following ${ }^{18}$ :

\subsubsection{Questions on the distribution of ideologies}

Respondents were asked to indicate their own and their colleagues ${ }^{19}$ ideologies on social or ethical issues, economic issues, and overall, using the familiar political left-right spectrum and 7-point scales $(1=$ Very leftleaning, $4=$ Moderate, $7=$ Very right-leaning).

\subsubsection{Questions on ideological hostility}

To assess participants' own experience of ideology-related hostility in philosophy, subjects were asked (1) how hostile the climate in their field is toward their own political beliefs, (2) how often they refrain from expressing their political beliefs to colleagues for fear of negative consequences, and (3) how often they think colleagues would discriminate against them on the basis of their ideology (5-point scales were used; $1=$ Not at all hostile, $3=$ Moderately hostile, $5=$ Extremely hostile, and $1=$ Never; 3 = Occasionally, $5=$ All the time). Participants were also asked to speculate about the hostility they believed left- or right-leaning colleagues might experience due to their ideology. The same questions and scales were used as before, but with the context changed from self to others.

We also added one question asking participants whether they would be reluctant to defend their own argument if it led to a left-leaning conclusion, and one question on whether they would be reluctant to do so if the argument led to a right-leaning conclusion. Our thought was that ideological hostility might not only emerge in relation to people but also in relation to contents, manifesting itself, for instance, in an aversion to support counterideological conclusions, claims, arguments, findings, and so on (Stevens et al., 2018). We reasoned that a strong reluctance to defend one's own arguments when they lead to counter-ideological conclusions also reflects an interesting asymmetric allegiance to an ideology over academic debate and constructive discourse.

\subsubsection{Questions on willingness to discriminate}

Two sets of four questions captured what we (following others; Brandt et al., 2014) conceptualized as participants' willingness to discriminate (henceforth 'WTD') against left- or right-leaning individuals or contents in their field. Specifically, we asked participants how often (on a 5-point scale: $1=\mathrm{Never}$, $3=$ Occasionally, $5=$ All the time) they would be negatively influenced in their decision on a grant application or a paper if that application or paper seemed to them to take a politically left- or right-leaning perspective, how 
often they would be reluctant to invite a colleague to symposia who is known to be left- or right-leaning, and how often they would be inclined to choose the more right- or left-leaning job candidate of two equally qualified applicants in hiring. ${ }^{20}$ Using the same questions and scales but with the context changed from self to others, we then also asked participants about their colleagues' behavior with respect to these four issues.

\subsubsection{Questions on justification}

Finally, participants were asked two justification-related questions: "how justified is discrimination (e.g., in hiring/promotion decisions, grants, or manuscript reviews) against left- or right-leaning individuals in your field?" ( $1=$ Not at all justified, $3=$ Neither justified nor unjustified, $5=$ Extremely justified), and "How often should politically left- or rightleaning ideas, theories, or critiques be discussed in the areas of philosophy where political viewpoints matter?" $(1=$ Never, $3=$ Occasionally or sometimes, $5=$ All the time). Our reasoning was that when participants hold that a left- or right-leaning idea, theory, or critique should, for instance, never be discussed, then they take it to be justified that it is never discussed.

In addition to these four types of questions, we also left a 'Free Response' section at the end of the survey, asking participants whether there was anything else they wanted to add about what they had seen or personally experienced in their field with regard to their political beliefs. The free comments yielded qualitative data in addition to the quantitative evidence derived from the scaled answers to questions 1-4.

\section{Results (quantitative data)}

\subsection{Distribution of ideological viewpoints and results on (H1)}

As predicted with (H1), participants were primarily left-leaning $(M=2.69$, $S D=1.49), t(793)=-24.77, p<.001,95 \%$ CI $[2.56,2.90]$ (see Table 2), analytic philosophers identifying as slightly less so $(M=2.79, S D=1.50)$ than

Table 2. Ideology of participants.

\begin{tabular}{lccc}
\hline & $\begin{array}{c}\text { Overall, count } \\
\text { (percent) }\end{array}$ & $\begin{array}{c}\text { Social/ethical issues, count } \\
\text { (percent) }\end{array}$ & $\begin{array}{c}\text { Economic issues, count } \\
\text { (percent) }\end{array}$ \\
\hline Very left-leaning & $160(20.2 \%)$ & $210(26.5 \%)$ & $170(21.4 \%)$ \\
Left-leaning & $309(38.9 \%)$ & $305(38.5 \%)$ & $289(36.4 \%)$ \\
$\begin{array}{l}\text { Somewhat left- } \\
\quad \text { leaning }\end{array}$ & $125(15.7 \%)$ & $105(13.2 \%)$ & $118(14.9 \%)$ \\
$\begin{array}{l}\text { Moderate } \\
\text { Somewhat right- }\end{array}$ & $87(11.0 \%)$ & $60(7.6 \%)$ & $75(9.5 \%)$ \\
$\quad$ leaning & $59(7.4 \%)$ & $55(6.9 \%)$ & $69(8.7 \%)$ \\
Right-leaning & $41(5.2 \%)$ & $37(4.7 \%)$ & $53(6.7 \%)$ \\
Very right-leaning & $13(1.6 \%)$ & $21(2.6 \%)$ & $19(2.4 \%)$ \\
\hline
\end{tabular}


continental philosophers $(M=2.47, S D=1.42), t(675)=-2.60, p=.01,95 \% \mathrm{CI}$ $[-.56,-.08]$ (see Table 4, Figure 3). Overall, $74.8 \%$ were left-leaning $(20.2 \%$ 'very left-leaning'), while $14.2 \%$ were right-leaning (1.6\% 'very right-leaning'). Only $11 \%$ were moderates (for classification by rank and subfield, see Tables 3 and 5, Figures 2 and 4). On economic issues $(M=2.55, S D=1.56)$ and social or ethical issues $(M=2.77, S D=1.61)$, participants also clearly leaned left (see Table 2). Participants also perceived their colleagues as primarily left-leaning $(M=2.50, S D=.86), t(788)=-48.99, p<.001,95 \%$ CI $[-1.56,-1.44]$, and, as a post hoc paired-samples t-test (not pre-registered) indicated, they viewed them as more left-leaning than themselves $\left(M_{\text {diff }}=.193, S D=1.81\right), t$ $(788)=2.99, p<.001,95 \%$ CI $[.07, .32] .^{21}$

\subsection{Ideological hostility and results on (H2)}

Supporting (H2), a significant correlation was found between ideology and reported personal experience of hostility $r(794)=.47, p<.001$ (see Table 6). The more right-leaning the participant, the more hostility they reported personally experiencing from colleagues, and, overall, the more left-leaning the participant, the less hostility they reported personally experiencing. Participants also perceived right-leaning individuals in the field $(M=2.79, S D=.89)$ as experiencing more hostility than left-leaning subjects $(M=1.78, S D=.64), t(779)=24.40$, $p<.001,95 \%$ CI $[.93,1.09] d=1.30$. Looking at it another way, binning participants by ideology (binned: $1-3=$ left-leaning, $4=$ moderate, 57 = right-leaning), a post hoc (not pre-registered) one-way ANOVA revealed significant differences in experiences of hostility by ideology, $F(2,793)=151.09$, $p<.001$. Post hoc Bonferroni comparisons indicated that right-leaning participants reported experiencing more hostility than moderate participants $\left(M_{\text {diff }}=.78, p<.001\right)$ and left-leaning participants $\left(M_{\text {diff }}=1.50, p<.001\right)$, and that moderate participants reported experiencing more hostility than left-leaning participants $\left(M_{\text {diff }}=.72, p<.001\right)$.

Turning now to an ideological aversion against or preference for contents, participants reported that they would be more reluctant to defend their own argument if it led to a right-leaning conclusion $(M=2.61, S D=1.16)$ than if it led to a left-leaning one $(M=1.94, S D=1.02), t(647)=-13.39, p<.001$, $95 \%$ CI $[-.78,-.58] d=-.61$. There was also a weak tendency for more leftleaning participants to express more reluctance to defend a right-leaning conclusion $(r=-.09, p=.023)$ (Table 6). There was, however, no association between ideology and how often participants would be reluctant to defend their argument if it led to a left-leaning conclusion $(r=.06, p=.126)$. These findings point toward an apparent stigma held by most participants, regardless of their political ideology, against defending right-leaning conclusions. Considered together with our other results, this reluctance to defend rightleaning conclusions may be the by-product of perceived or actual 


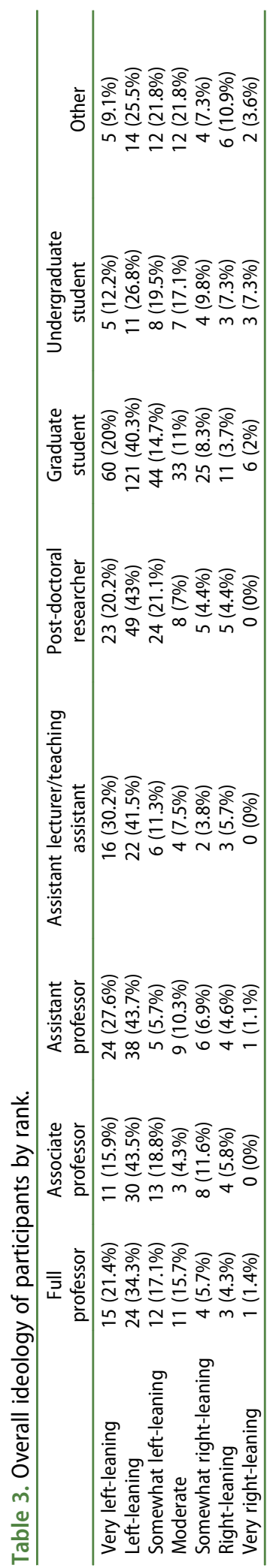


Table 4. Overall ideology of participants by tradition.

\begin{tabular}{lccc}
\hline & Continental philosophy & Analytic philosophy & Other \\
Very left-leaning & $53(24.2 \%)$ & $74(16.2 \%)$ & $31(29.2 \%)$ \\
Left-leaning & $91(41.6 \%)$ & $189(41.3 \%)$ & $27(25.5 \%)$ \\
Somewhat left-leaning & $33(15.1 \%)$ & $69(15.1 \%)$ & $20(18.9 \%)$ \\
Moderate & $18(8.2 \%)$ & $51(11.1 \%)$ & $18(17 \%)$ \\
Somewhat right-leaning & $10(4.6 \%)$ & $44(9.6 \%)$ & $3(2.8 \%)$ \\
Right-leaning & $12(5.5 \%)$ & $22(4.8 \%)$ & $6(5.7 \%)$ \\
Very right-leaning & $2(0.9 \%)$ & $9(2 \%)$ & $1(0.9 \%)$ \\
\hline
\end{tabular}

ideological discrimination within the field. It suggests the presence of ideological "self-censorship" (Bar Tal, 2017; Maroja, 2019).

\subsection{WTD and results on (H3)}

As predicted with (H3), significant correlations were found between ideology and the WTD items (i.e., left- or right-leaning on paper review, grant review, symposia invitation, hiring; see Table 6). The more left-leaning the participant, the more frequently a right-leaning perspective or individual would be viewed negatively in assessing grant applications $(r=-.37$, $p<.001)$, evaluating papers $(r=-.31, p<.001)$, inviting colleagues to symposia $(r=-.28, p<.001)$, and making hiring decisions involving two otherwise equally qualified candidates $(r=-.36, p<.001)$. On the other side, the more right-leaning the participant, the more frequently a left-leaning perspective or individual would be viewed negatively in assessing grant applications $(r=.21, p<.001)$, evaluating papers $(r=.15, p<.001)$, inviting colleagues to symposia $(r=.08, p=.04)$, and making hiring decisions $(r=.24, p<.001)$.

Overall, however, WTD against right-leaning perspectives or individuals $(M=2.18, S D=.88)$ was significantly greater than WTD against left-leaning perspectives or individuals $(M=1.63, S D=.56), t(732)=16.11, p<.001,95 \%$ CI $[.48, .61] d=.74$. To see this differently, consider the binned percentages (participants who responded 'occasionally,' 'frequently,' or 'all the time') for the WTD questions, broken down by ideology (binned: 1-3 = left-leaning, $4=$ moderate, $5-7=$ right-leaning; see Figure 5). Of the left-leaning participants, 32\% indicated WTD against right-leaning papers, $42 \%$ against rightleaning grants, 38\% against right-leaning symposia speakers, and 56\% against right-leaning job candidates, at least occasionally. In contrast, among rightleaning participants, $20 \%$ indicated WTD against left-leaning papers, $23 \%$ against left-leaning grants, $12 \%$ against left-leaning symposia, and $46 \%$ against a left-leaning job candidate, at least occasionally (see Figure 5).

Given the apparent skew in the percentages for WTD by ideology, via post hoc analyses (not pre-registered), we tested for left-right differences in frequency of WTD. Four new variables were created for WTD against 


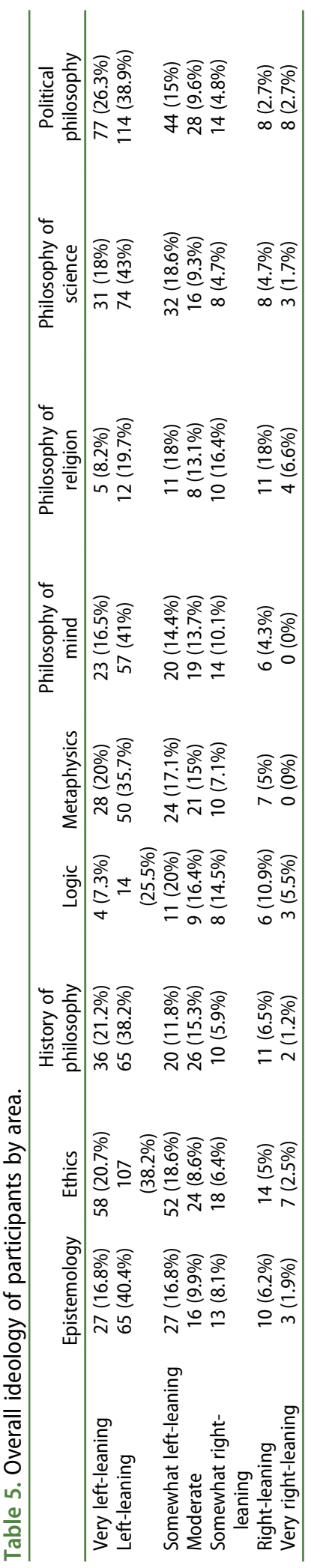




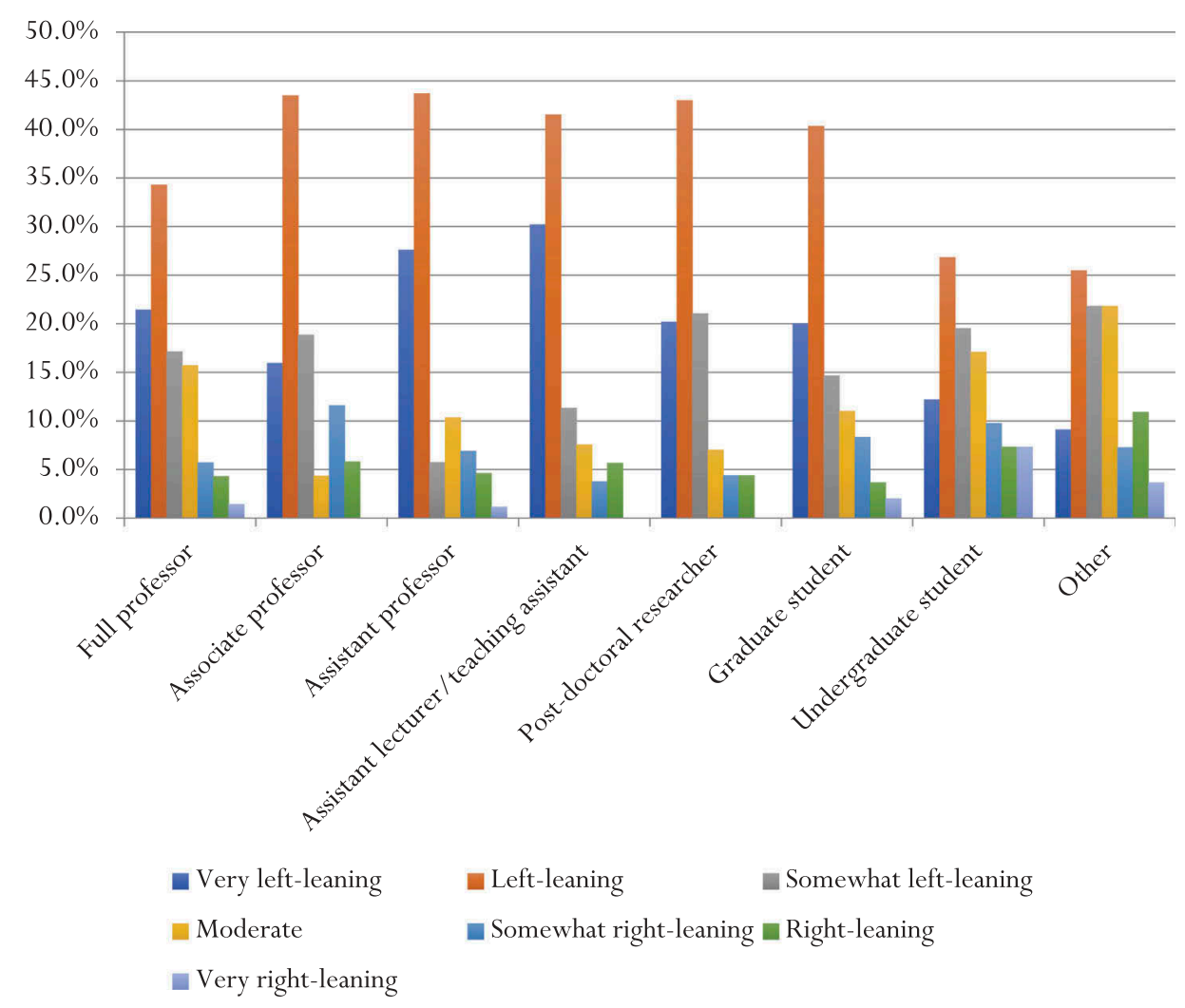

Figure 2. Percentages of participants by rank and ideology.

the opposition (i.e., left vs. right and vice versa) for the four dimensions (reviewing a grant, assessing a paper, symposia invite, hiring). For ideology for these tests, we used the binned variable for ideology (1-3 = leftleaning, 4 = moderate, $5-7$ = right-leaning). ${ }^{22}$

Multiple independent sample t-tests to compare WTD against the opposition for left- versus right-leaning participants showed that left-leaning participants $(M=2.35, \mathrm{SD}=.98)$ were more likely than right-leaning ones $(M=1.99, \mathrm{SD}=.80)$ to view negatively the grant application of the opposing ideology, $t(668)=3.62, p<.001,95 \%$ CI $[.17, .56] d=.38$. They $(M=2.14$, $\mathrm{SD}=.98)$ were also more likely than right-leaning participants $(M=1.83$, $\mathrm{SD}=.83)$ to view negatively a paper of the opposing ideology, $t(669)=3.04$, $p<.001,95 \%$ CI $[.11, .50] d=.32$. Furthermore, they $(M=2.25, \mathrm{SD}=1.07)$ were more likely than right-leaning participants $(M=1.55, \mathrm{SD}=.79)$ to be less willing to invite colleagues of the opposing ideology to symposia, $t$ $(668)=6.51, p<.001,95 \%$ CI $[.49, .91] d=.68$. Lastly, left-leaning participants $(M=2.67, \mathrm{SD}=1.19)$ were more likely than right-leaning participants $(M=2.37, \mathrm{SD}=1.03)$ to not be willing to hire someone of the opposing ideology, $t(668)=2.45, p=.015,95 \%$ CI $[.06, .54] d=.26{ }^{23}$ 


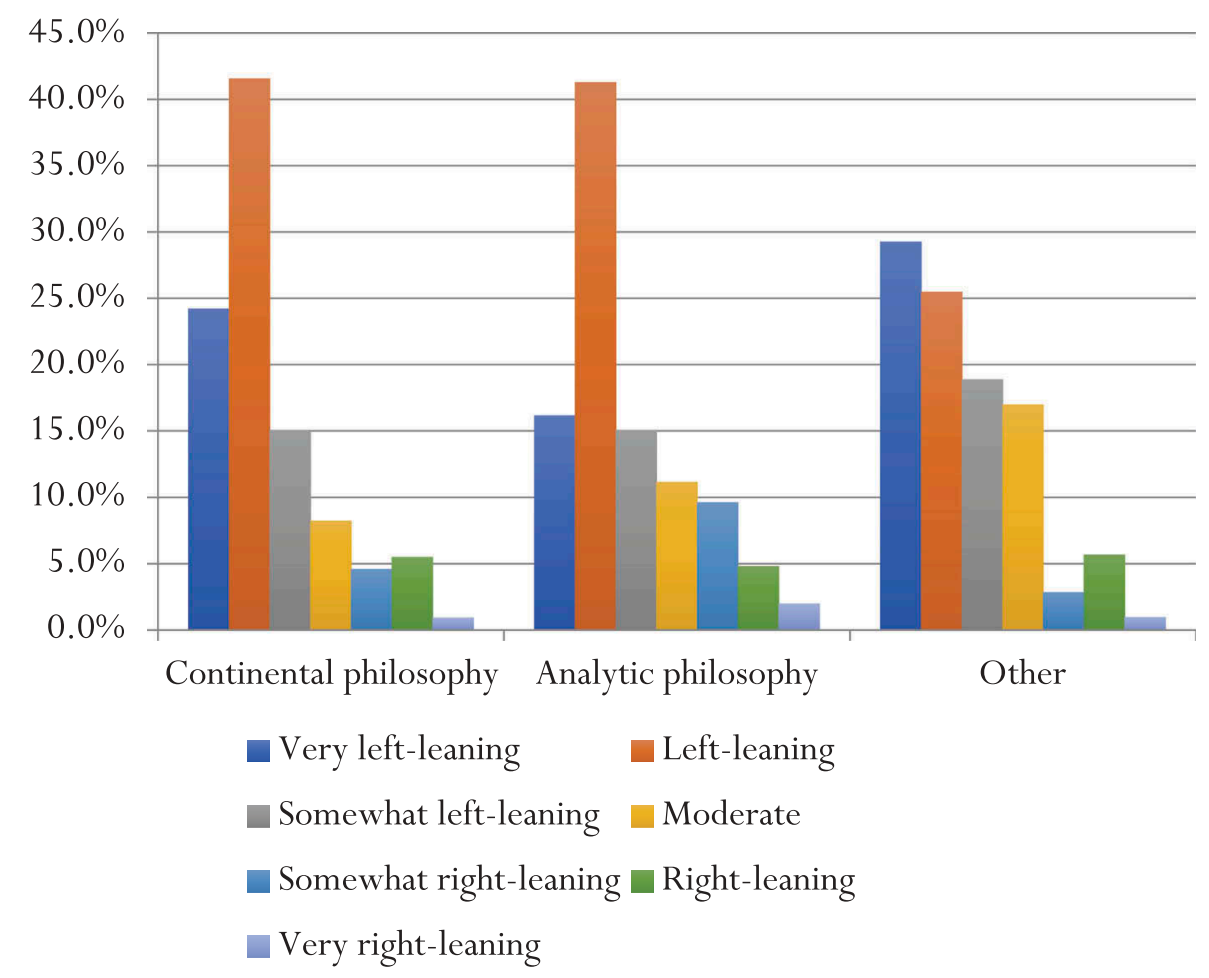

Figure 3. Percentages of participants by tradition and ideology.

Collectively, these analyses indicate that left-leaning participants' WTD against the right was greater than right-leaning participants' WTD against the left (see Figures $5 \& 6$ for WTD by rank).

Finally, there was no statistically significant difference between analytic $(M=1.64, \mathrm{SD}=.57)$ and continental $(M=1.61, \mathrm{SD}=.52)$ philosophers for WTD against left-leaning perspectives or colleagues, $t(641)=-.50, p=.62$, $95 \%$ CI $[-.12, .07]$. A statistically significant difference did emerge, however, for WTD against right-leaning colleagues, $t(638)=2.89, p=.004,95 \% \mathrm{CI}$ $[.07, .36]$ : continental philosophers $(M=2.32, \mathrm{SD}=.92)$ were willing to discriminate against right-leaning perspectives or colleagues more frequently than analytic philosophers $(M=2.10, \mathrm{SD}=.85)$.

Moving from participants' reports on how they themselves would act to their reports on how they thought others would act, we found that the more left-leaning the participant, the more likely they were to believe that a leftleaning perspective or individual would be treated negatively by colleagues in the mentioned contexts (Table 6; grant application, $r=-.26, p<.001$; paper review, $r=-.27, p<.001$; symposia invitation, $r=-.31, p=.04$; hiring decisions, $r=-.27, p<.001)$. The more right-leaning the participant, the more likely they were to believe that a right-leaning perspective or individual would be viewed negatively by colleagues in these contexts (grant 


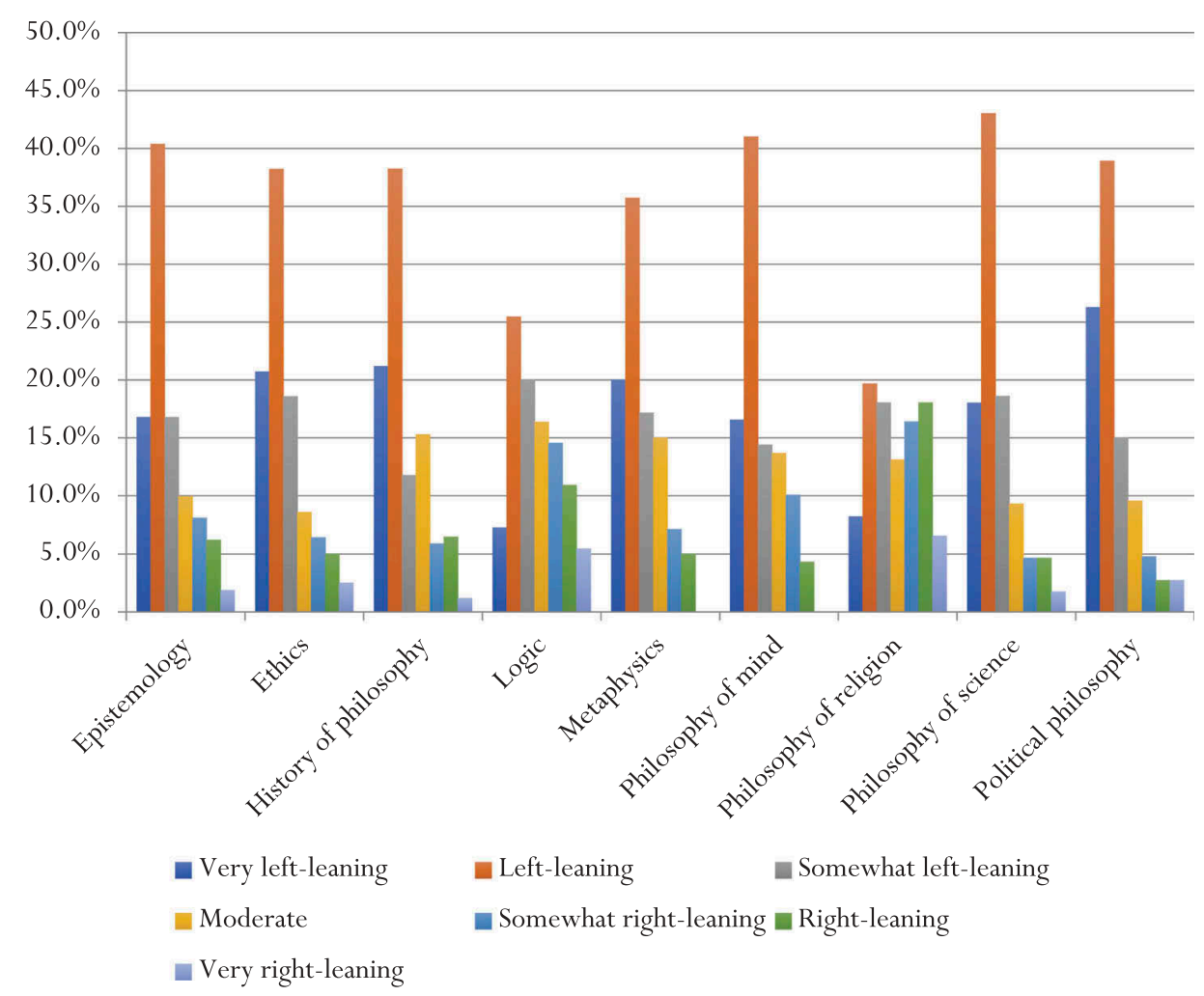

Figure 4. Percentages of participants by area and ideology.

application, $r=.39, p<.001$; paper review, $r=.36, p<.001$; symposia invitation, $r=.31, p<.001$; hiring decisions, $r=.34, p<.001)$. Overall, however, participants reported believing that colleagues would engage in discrimination against right-leaning individuals $(M=2.74, S D=.87)$ more often than against left-leaning individuals $(M=1.97, S D=.70), t$ $(652)=17.30, p<.001,95 \%$ CI $[.68, .85] d=.97$.

\subsection{Justification of discrimination and results on (H4)}

A total of 398 participants (50.1\%) indicated that discrimination against rightleaning contents or individuals in the field (in hiring or promotion decisions, grants, or manuscript reviews) is not at all justified (scale-point 1 on the scale of 1-5). A total of 436 (54.9\%) indicated the same with respect to left-leaning contents or individuals. A total of 365 participants (51.34\%) indicated that both types of discrimination are not at all justified.

Moreover, consistent with prediction (H4), there was a significant association between ideology and justification of discrimination against rightleaning individuals in the field $(r=-.37, p<.001)$ (see Table 6). The more left-leaning the participant, the more justified they believed discrimination 
Table 6. Correlations of ideology with variables and items, and variable and item means (sds).

\begin{tabular}{lcc}
\hline & Political ideology & $M(\mathrm{sd})$ \\
\hline Political ideology & - & $2.69(1.49)$ \\
Hostility (personal) composite variable & $.47^{* * *}$ & $2.21(1.02)$ \\
WTD Right-leaning paper & $-.31^{* * *}$ & $1.99(.95)$ \\
WTD Right-leaning grant & $-.37^{* * *}$ & $2.18(.98)$ \\
WTD Right-leaning symposia guest & $-.28^{* * *}$ & $2.10(1.08)$ \\
WTD Right-leaning hire & $-.36^{* * *}$ & $2.44(1.20)$ \\
WTD Left-leaning paper & $.15^{* * *}$ & $1.60(.73)$ \\
WTD Left-leaning grant & $.21^{* * *}$ & $1.68(.73)$ \\
WTD Left-leaning symposia guest & $.08^{*}$ & $1.42(.64)$ \\
WTD Left-leaning hire & $.39^{* * *}$ & $1.85(.89)$ \\
Colleagues WTD Right-leaning paper & $.36^{* * *}$ & $2.62(.96)$ \\
Colleagues WTD Right-leaning grant & $.39^{* * *}$ & $2.73(.94)$ \\
Colleagues WTD Right-leaning symposia guest & $.31^{* * *}$ & $2.73(.99)$ \\
Colleagues WTD Right-leaning hire & $.34^{* * *}$ & $2.89(.99)$ \\
Colleagues WTD Left-leaning paper & $-.27^{* * *}$ & $1.95(.79)$ \\
Colleagues WTD Left-leaning grant & $-.26^{* * *}$ & $2.01(.81)$ \\
Colleagues WTD Left-leaning symposia guest & $-.31^{* * *}$ & $1.88(.82)$ \\
Colleagues WTD Left-leaning hire & $-.27^{* * *}$ & $2.08(.83)$ \\
Justified discrimination - right-leaning individual & $-.37^{* * *}$ & $1.90(1.21)$ \\
Justified discrimination-left-leaning individual & .000 & $1.64(.95)$ \\
Fit - right-leaning individual & -.05 & $2.65(.85)$ \\
Fit - left-leaning individual & .05 & $3.67(.81)$ \\
How often should right-leaning ideas, theories, critiques be discussed & $.13^{* *}$ & $3.91(.72)$ \\
How often should left-leaning ideas, theories, critiques be discussed & -.07 & $4.02(.61)$ \\
Defend right-leaning conclusion to argument & $-.09^{*}$ & $2.61(1.16)$ \\
Defend left-leaning conclusion to argument & .06 & $1.94(1.02)$ \\
\hline
\end{tabular}

${ }^{*} p<.05,{ }^{* *} p<.01,{ }^{* * *} p<.001$

against right-leaning individuals to be. Against (H4), however, there was no significant association between ideology and justification of discrimination against left-leaning individuals $(r=.000, p=.991)$.

Providing further insights into participants' views on whether the treatment of certain ideological contents is justified, we also found that the more right-leaning the participant, the more frequent the indication that rightleaning ideas, theories, or critiques should be discussed more often in the relevant areas $(r=.13, p=.001)$ (Table 6). However, there was no significant association between ideology and opinions on how often left-leaning ideas, theories, or critiques should be discussed $(r=-.07, p=.071)$. Notice too that while there was, overall, a significant difference between how often participants believed that left-leaning ideas, theories, or critiques should be discussed (when relevant) $(M=4.02, S D=.62)$ compared to right-leaning ones $(M=3.91, S D=.72), t(645)=5.52, p<.001,95 \%$ CI $[.08, .16] d=.16)$, the means for both kinds of contents are quite high and near the item scalepoint of 4 (i.e., 'frequently'). Practically speaking, overall, participants reported that both should be discussed in the relevant areas relatively frequently, and the effect size is small. 


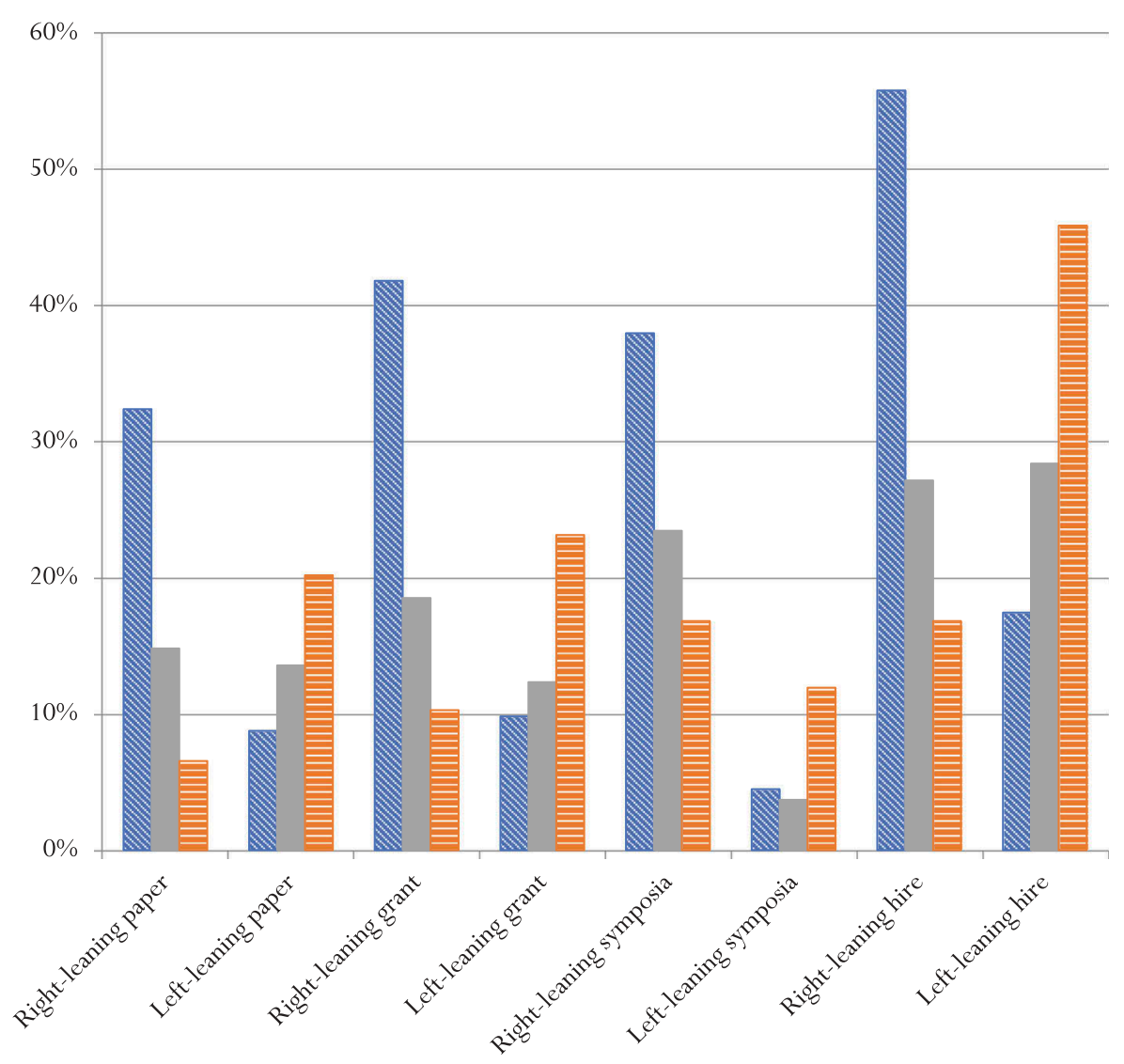

Note: Scores of 3 mean "occassionally" and scores of 5 mean "all the time"

$$
\text { \$ Left-leaning } \quad \text { Moderate ERight-leaning }
$$

Figure 5. Percentages of participants answering 3-5 on the "willingness to discriminate" items.

\section{Results (qualitative data)}

We now turn from the findings of the quantitative analyses to the "free response" that participants could give at the end of the survey. These responses provide qualitative data that help cast further light on the quantitative findings, for many free responses mention concrete examples of the ideological bias, discrimination, or hostility that respondents experienced, witnessed, or heard about in the field. A total of 231 participants $(29.1 \%$ of the sample) left comments in the "free response" section. We classified them into different, non-exclusive categories. ${ }^{24}$ Our four main categories were the following:

(1) Underrepresentation of or hostility toward left-leaning individuals or views 


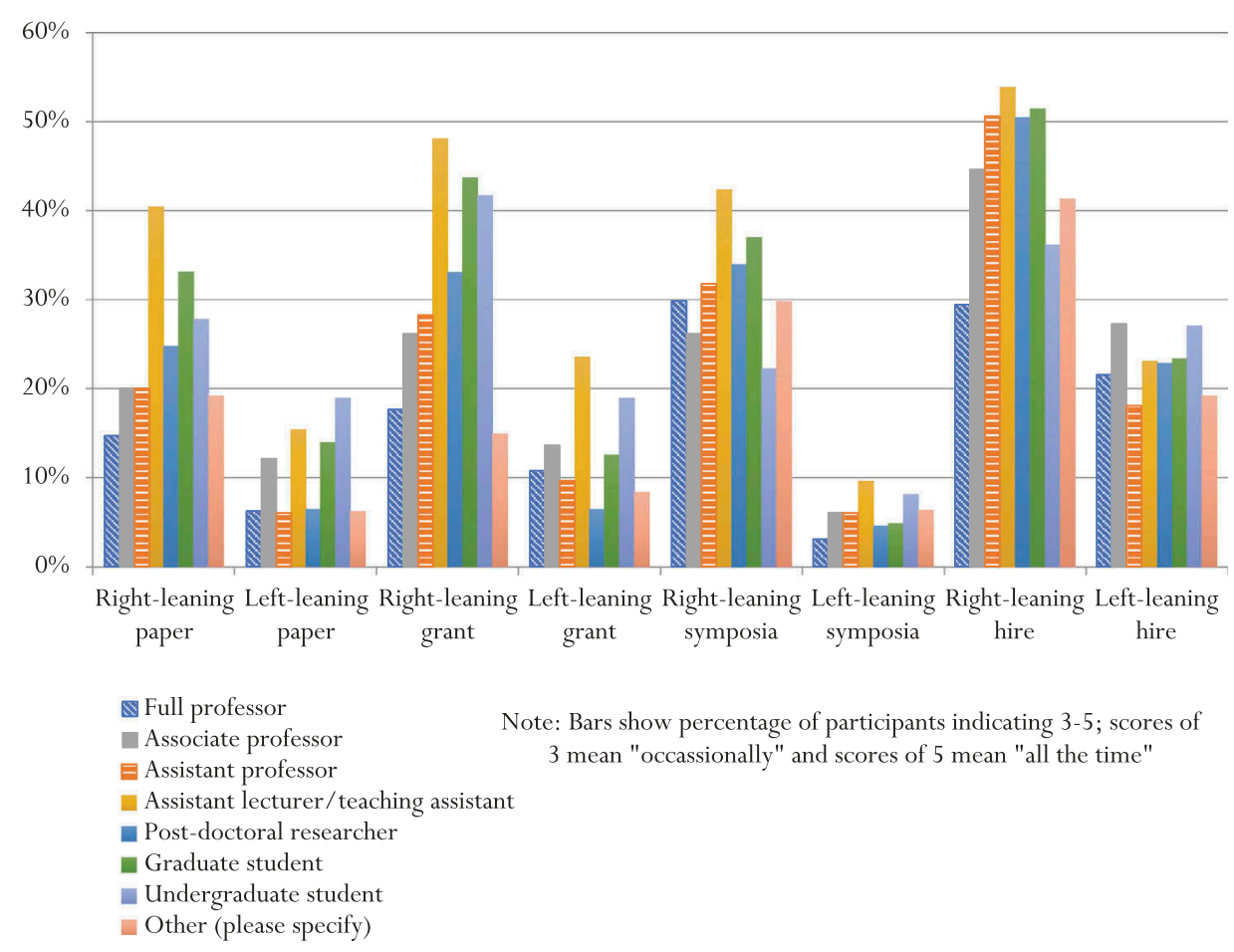

Figure 6. Percentages of participants by rank answering 3-5 on the "willingness to discriminate" items.

(2) Hostility from the left against the left

(3) Underrepresentation of or hostility toward right-leaning individuals or views

(4) Doubts about ideological bias, hostility, or discrimination

We shall briefly consider some of the responses classified as 1-4. A list of all responses is freely available on our OSF platform. ${ }^{25}$

\subsection{Underrepresentation of or hostility toward left-leaning individuals or views}

Twenty-eight responses fell into this category. ${ }^{26}$ Overall, people who were very left-leaning reported significantly more experiences of bias, discrimination, and hostility than liberals or moderately progressives, writing, for instance,

In my experience the discrimination is against those ${ }^{*}$ critical of liberalism ${ }^{\star}$ from a left-wing/feminist/anti-colonial perspective. Liberal left-wing philosophers don't have any difficulties - if anything, theirs is the dominant view. But anyone further left will experience a hostile environment (e.g., anarchists, Marxists). $(68)^{27}$ 
I do not think milquetoast liberal views are marginalized. I think more radical, broadly 'left,' communist, feminist, racial liberationist, etc. views are. (95; and see also $98,137,152,172,175,218,223$ )

I had a grant application rejected in the last few years, and one of the reasons stated was that I am a feminist and a feminist cannot conduct a fair inquiry in the area of the grant application. (37)

Some respondents maintained that "neoliberalism" or the capitalist "system" itself contributes to an ideological bias against, and an underrepresentation of, radical left-wing views and individuals in academic philosophy $(67,51)$. Others suggested that hostility toward (radical) left-leaning views might, in fact, be internal or related to certain philosophical traditions:

Analytic philosophy is built on a fairly right wing foundation anyway, of the individual logical man using atomised premises to create an argument. When one deviates from this, the boundaries of the discipline are heavily policed. (79; see also 137)

The antipathy towards 'continental' philosophy also sometimes plays out in hostility towards left-wing political critique springing from that tradition. (175)

\subsection{Hostility from the left against the left}

Echoing some of the remarks just mentioned but more explicitly stating the source of hostility, one respondent wrote about the marginalization of certain left-leaning views by a "liberal majority" (95), while another added that the "discipline is politically liberal, which means hostile to both conservative and socialist critique" (172). Comments of this kind suggest that left-leaning individuals may be hostile to others on their own ideological side because they are too left. Adding further complexity to the phenomenon, people who self-identified as moderately left-leaning also sometimes reported that they faced hostility for not being left enough by those on the far left. In fact, 11 responses mentioned hostility against moderately left-leaning individuals or views from the far end of their own political side, saying, for instance:

I for one did not feel comfortable voicing pro-Hillary sentiment during the primary, mainly for fear of censure from more left-leaning colleagues. (27)

I said that I am left-leaning and sometimes feel pressure to stay quiet about my beliefs. [...] I think this pressure is not coming from right-wing members of the profession, but from left-wing members who might believe that I am not left-wing enough (170, see also 231, 12, 16 99, 107, 52, 111, 115, 209) 


\subsection{Underrepresentation of or hostility toward right-leaning individuals or views}

Seventy-six responses fell into this category, sometimes containing colorful expressions of experiences of hostility such as, for instance,

If my professional colleagues knew that I am moderately right-wing then half of them would call me a 'subhuman pig' and treat me accordingly. The other half would keep silent for fear of being next. (1)

Several respondents also noted that right-leaning subjects were the preferred targets of jokes in academic philosophy:

Comments and jokes about those on the right are frequent, and this makes it difficult to gauge the true balance of opinion as any right-leaning individual is likely to remain quiet. (210; see also 60, 231).

Another respondent wrote,

I have seen large-scale organised walk-outs by students at visiting lectures by senior academics who are known to be politically right-leaning. [...] [A] fairly large number of students and academics in philosophy tend to give the least charitable/most extreme interpretation of right-leaning claims made by others in their field. (182)

Many left-leaning respondents were, in fact, open about their WTD against, for instance, far right-leaning individuals and views, though they tended to suggest a different attitude toward moderately right-leaning ones and sometimes distinguished between right-leaning views on social as opposed to economic issues:

I would not invite a far-right speaker for a conference, but I don't think this tells us anything about my inclinations to invite people from the center right. (73)

I would loathe to hire a colleague who had views that had classist, racist, sexist, or nationalist implications, due to workplace issues. Economic views seem less directly relevant to the workplace environment. (132; see also 131, 23)

Libertarian ideas about minimum wages and social welfare seem to be more tolerated than conservative arguments that challenge left-leaning views on social or ethical issues:

I suspect that men and women are predisposed to have different interests, and that this accounts for the disparities in gender ratios across disciplines/professions. Yet this view is not one I am able to voice openly [...]. I don't know what reaction people would have if I were to make this view public, but I suspect it 'hostile' would be an understatement. (12)

It is worth noting too that when right-leaning participants reported experiences of hostility in the free responses, there was no comment to the effect that the hostility was coming from individuals from their own side of the political spectrum (either more radical or more moderate subjects). This 
contrasts with the free responses by left-leaning subjects about their leftleaning colleagues.

\subsection{Doubts about ideological bias, discrimination, and hostility}

Thirty-four responses fell into this category. Some claimed that ideological bias and discrimination in philosophy are rare, if not non-existent:

I have seen no evidence of systematic bias on the basis of political affiliation in 15 years of involvement in professional philosophy. (40; see also 180)

My field (at least in Europe) is dominated by left-leaning individuals, such as myself. I don't think this is the product of discrimination or anything sinister, however. (179)

In some responses, a subfield was taken to be free from discrimination because the decision-makers lack knowledge of the ideology of the individuals they decide on (29), or because ideology is irrelevant $(122,200)$. Many respondents thought the following:

The quality of arguments matters more than the orientation of political beliefs. I feel that both right-wing and left-wing beliefs are respected in my field as long as they are well-supported. (91; see also 57, 86, 139, 162, 164, 226).

Relatedly, a number of respondents claimed that right-wing ideas, in general, tend not to survive philosophical scrutiny:

Conservative ideas tend to lose in fair competition in the marketplace of ideas. They are given their chance, and are generally shown to be bad. People who accept many of them tend to be bad philosophers. (25; see also 85,120 )

I'd be inclined to negatively review a right-leaning paper for the simple fact that I believe, given the arguments, that the political right get things ${ }^{*}$ wrong*. We're talking about matters of objective truth here. (85; see also 120)

Neither the widespread endorsement of leftist positions nor the widespread rejection of conservative positions is a matter of ideological bias, any more so than there is a bias against Creationists among biologists. (146; see also 7, 103, 126, 128, 146, 149, $151,203)$

While many philosophers claimed that right-leaning views in general - that is, not only the extreme positions - are "wrong" or "bad" philosophy, we found no corresponding claim in the free responses with respect to leftleaning views. This was another significant difference between left-leaning participants and right-leaning participants when their free responses were compared. 


\section{General discussion}

The qualitative and quantitative data introduced provide intriguing insights into the political dynamics in the field of philosophy. To begin with, participants in our survey clearly leaned left $(74.8 \%$; with $20.2 \%$ 'very leftleaning'), while right-leaning subjects and moderates were minorities. This coheres with and extends research in other fields such associology or social psychology, which has found a majority of liberals and an underrepresentation of conservatives in these disciplines (Honeycutt \& Freberg, 2017; Inbar \& Lammers, 2012; Yancey, 2011). While the overall distribution of leftversus right-leaning individuals that we found in philosophy might be expected, one of the more surprising results is that there were, in fact, fewer moderates (11\%) in our sample than right-leaning individuals (14\%).

One factor contributing to the imbalance in the representation of ideological viewpoints might be an aversion and discrimination against right-leaning and moderate individuals. Our study does not directly show that they do contribute to it. It does, however, provide evidence that ideological hostility and a readiness to discriminate on the basis of ideology are not only real in philosophy, but also directed at various ideologies, including a moderate stance (moderate participants reported experiencing more hostility than left-leaning participants, but less than right-leaning participants). Our findings thus suggest that across the political spectrum, from very left-leaning to very right-leaning individuals, philosophers sometimes experience politically motivated hostility in the field which, in some cases, prevents them from expressing their viewpoints, from being taken seriously, and from contributing to debates. This is striking because, given the pervasiveness of explicit commitments to open-mindedness and inclusiveness among philosophers (Kidd, 2017; Kings, 2019; Riggs, 2010), philosophy departments, ${ }^{28}$ and organizations, ${ }^{29}$ one would expect the opposite.

Equally surprisingly, our qualitative data, combined with the quantitative findings, reveal a significant discrepancy between the beliefs of many philosophers that ideological bias and discrimination are either rare or nonexistent in the field, and the reports of a much larger amount of other philosophers of having actually experienced or witnessed them firsthand, or even being willing to engage in it themselves. Starting with the political right, the more right-leaning the participant was, the more hostility they reported personally experiencing from colleagues, and the stronger their impression that they and their political ideology would be negatively viewed in judgment- and decision-making in the field. The validity of this subjective impression was partly confirmed by the fact that the more left-leaning the participant was, the more frequent was their WTD against right-leaning individuals and contents in judgment- and decision-making. Similarly, the more left-leaning participants were, the stronger their impression that they 
themselves and their ideology would be negatively assessed in the mentioned contexts (although they did not report more experiences of hostility). This subjective impression too was partly confirmed by the fact that the more right-leaning the participant was, the more frequent their WTD against left-leaning individuals or contents in application or paper reviewing, conference invitations, and hiring.

These results provide support for the "ideological-conflict hypothesis" (Brandt et al., 2014) in suggesting that left-leaning individuals and rightleaning individuals are similarly intolerant against groups holding values inconsistent with their own. There are left-right asymmetries, however, that are noteworthy in the context of the ideological-conflict hypothesis. For instance, right-leaning individuals' WTD against left-leaning contents or individuals was less pronounced than left-leaning individuals' WTD against right-leaning contents or individuals. Additionally, both groups of participants tended to be more reluctant to defend arguments with right-leaning conclusions than those with left-leaning ones - an interesting finding suggesting ideological self-censoring among participants (Bar Tal, 2017; Maroja, 2019). Moreover, while we found that factions within the leftleaning side of the political spectrum are sometimes hostile against each other too, we could not detect a similar phenomenon among right-leaning subjects. Since moderately left-leaning individuals (e.g., liberals) and very left-leaning individuals share important features (e.g., an emphasis on equality; Arneson, 2015) that make them, despite their differences, fall on the same left side of the spectrum, we shall call this phenomenon intraideological hostility. In providing evidence of intra-ideological hostility, our study offers a new contribution to extant research on ideological hostility in academia, which has so far only revealed cross-ideological hostility (liberals vs. conservatives and vice versa) (Brandt et al., 2014; Honeycutt \& Freberg, 2017). It is an interesting question for future research whether intra-ideological hostility might, in fact, be stronger than cross-ideological hostility.

Independently of their strength, it is worth noting that hostility and discrimination against a particular ideology in philosophy or any other academic discipline need not be problematic. An aversion against creationists in biology or against flat-earthers in geology seems unobjectionable. The same might hold for individuals with certain ideologies in philosophy. If so, then one would expect members of the field to take discrimination against some subjects on the basis of their ideology to be justified. Indeed, we did find that the more left-leaning the participant was, the more justified they believed discrimination against right-leaning contents or individuals in the field to be, while the reverse did not hold. Yet, importantly, we also found that about half of the participants took discrimination against either left- or right-leaning contents or individuals in the field to be not justified at all, which starkly contrasts with the fact that many participants on both the left 
and the right in fact openly acknowledged that they would discriminate ${ }^{30}$ against contents or individuals of the opposite ideology.

Of course, even if the majority thought that acting in these ways is not justified, it might still be justified. We do not want to commit to any strong view on whether this is the case with respect to individuals or contents of either ideology. That is, we are open to the possibility that ideological bias, hostility, and discrimination are frequently justified. ${ }^{31}$ We do, however, believe that they are also often costly enough for the field of philosophy to consider taking steps to counteract them. ${ }^{32}$ There are two kinds of costs: epistemic costs and ethical ones.

\subsection{Epistemic costs}

Epistemic costs are negative effects on the reliability of belief formation and knowledge acquisition in the field. A bias against and lack of, say, feminist, moderate, or conservative (right-leaning) scholars in philosophy might be detrimental in this sense. Such a bias would reduce the scope of critical questions being asked, which would increase researchers' susceptibility to reasoning errors due to confirmation bias and group polarization, and might impede a convergence on truths (Longino, 2002, p. 132; Draper et al., 2013; Peters, 2019). The problem is particularly pressing in philosophy because philosophical claims are frequently affected by philosophers' political values, which emphasize some aspects of an issue while obscuring others. Additionally, different ideological convictions incline philosophers toward different conclusions in debates on, for instance, equality (Cohen, 2006), immigration (Hidalgo \& Freiman, 2016), social welfare (Rajczi, 2014), abortion (McLachlan, 1977), implicit bias (Allen-Hermanson, 2017b), affirmative action (Shields \& Dunn, 2016, p. 196), the heritability of intelligence (Sesardic, 2010), cognitive-difference research (Kourany, 2016), values in science (Hicks, 2011), and more. Since claims in these areas of philosophical inquiry are often based on political values and cannot be easily empirically tested, social criticism is important for philosophers to avoid blind spots and errors in their reasoning.

A study by Gampa et al. (2019) suggests that these errors are not just possible but likely. Gampa et al. asked liberals and conservatives to evaluate the logical soundness of classically structured logical syllogisms supporting liberal or conservative beliefs. They found that

[Both] liberals and conservatives frequently evaluated the logical structure of entire arguments based on the believability of arguments' conclusions, leading to predictable patterns of logical errors. As a result, liberals were better at identifying flawed arguments supporting conservative beliefs, and conservatives were better at identifying flawed arguments supporting liberal beliefs. (Gampa et al., 2019, p. 1) 
These findings highlight the importance of ideological opponents in valueladen debates, which are particularly common in philosophy, to correct for reasoning biases and possibly harness opposing individuals' ideologies for epistemic group-level benefits (a "Mandevillian" effect; Peters, forthcoming).

However, a lack or a swift dismissal of, for instance, very left-leaning, moderate, or right-leaning minority beliefs in philosophy would not only weaken the reliability of philosophical belief formation. It could also lead scholars to overlook meaningful research questions (Jussim et al., 2018; Richardson, 2010), and it might, given the reduced social checking of reasoning, cause scholars inside and outside philosophy as well as the public to distrust philosophical research (Rolin, 2002, p. 100; Kornblith, 1999, p. 190).

Some "free responses" suggested that an aversion and discrimination against right-leaning individuals and views, in particular, are, in fact, epistemically warranted because such individuals are less likely to reason correctly, and their views tend to be misguided. However, any claim to the effect that right-leaning individuals are in general less intelligent and philosophically capable than left-leaning subjects is most likely false, due to its broad scope and the diverse distribution of intellectual capacities (Duarte et al., 2015, p. 9). Moreover, even advocates of misguided minority views might be epistemically beneficial in challenging and/or motivating those holding the accurate views to articulate and keep in sight the reasons for their views (Longino, 2002, p. 131; Peters 2019). An absence of and/or discrimination against misguided minority positions may also increase the probability that subjects come to hold widely shared correct views without being able to properly defend them (Maroja, 2019).

\subsection{Ethical costs}

Ethical costs are effects of ideological bias and a lack of ideological diversity, which are related to a violation of what subjects take to be morally valuable, such as, for instance, fairness, equality, or social justice. The ideological hostility and discrimination we found create ethical costs in that they violate moral principles that many philosophers (Kidd, 2017; Kings, 2019; Riggs, 2010) and philosophical institutions commit themselves to. For example, in Europe, the Faculty of Philosophy at Cambridge University stresses that it is "committed to equality, diversity, and inclusion." ${ }^{33}$ Oxford University too has a "commitment to fostering an inclusive culture which promotes equality, values diversity, and maintains a working, learning, and social environment in which the rights and dignity of all its staff and students are respected."34 Turning to the United States, the Department of Philosophy at New York University emphasizes, "We do not tolerate [...] discrimination, and we strongly support efforts to remove barriers to inclusiveness in philosophy as a discipline." ${ }^{35}$ In the same vein, the Department of Philosophy at Rutgers 
University writes "Philosophy both requires and fosters norms of civil, inclusive discourse. [...] No topic or claim is too obvious or controversial to be discussed." ${ }^{36}$ Similarly, the American Philosophical Association "acknowledges that in all their professional interactions and relations, philosophers are responsible for: Treating others fairly, equitably, and with dignity" and "respecting the philosophical opinions and traditions of others, without disparaging those who hold positions at odds with one's own."37

It may be untenable to hold that "all are welcome," for, as Popper (1945) suggests, if "we are not prepared to defend a tolerant society against the onslaught of the intolerant, then the tolerant will be destroyed, and tolerance with them" (p. 360). However, many political philosophers have convincingly argued that it is usually morally and politically wise to "tolerate the intolerant" as long as nobody's safety is in danger (Rawls, 1971; Walzer, 1997). Also, while it is not always easy to draw the lines between what is a dangerous ideological view and what is not, it seems reasonable to assume that most left-leaning and right-leaning philosophers are not putting people's safety at risk.

\section{Limitations}

\subsection{Low response rate}

When the survey was sent out via the PHILOS-L list server, the server had 11,388 subscribers. The initial response rate was $9.39 \%$. After data exclusions, the final response rate was $6.97 \%$. This is $1 \mathrm{low}^{38}$ and introduces the risk that the people who did not respond have characteristics that are different than those of the people who did.

However, low response rates in online surveys are common, and studies, in fact, found no direct correlation between response rate and validity (Visser et al., 1996; Morton et al. 2012). Relatedly, recent evaluations of surveys with response rates ranging from $5 \%$ to $54 \%$ conclude that studies with a lower response are frequently only marginally less accurate than those with much higher rates (Holbrook et al., 2007). Thus, a low response rate does not automatically mean that the study results have low validity, especially not when the absolute numbers are high, as in our case (Templeton et al., 1997).

Moreover, when respondent characteristics are representative of those of non-respondents, low response rates are not problematic at all (Sax et al., 2003). We cannot verify whether respondent characteristics in our sample were representative of the field of philosophy as a whole, but our sample is similar to samples of related studies. For instance, our participants, just as those of these other studies, were mostly male, White, liberal or left, and analytic philosophers ${ }^{39}$ (Botts et al., 2014; Bourget \& Chalmers, 2014; 
Paxton et al., 2012; Yancey, 2011), suggesting that our sample is not especially unrepresentative of the field.

The generalizability and validity of our results are also supported by the fact that key trends in our data (e.g., an underrepresentation of right-leaning subjects, and cross-ideological hostility) are not outliers. They are, in fact, consistent with those from various related surveys of the field (e.g., Honeycutt \& Freberg, 2017; Weinberg, 2016; Yancey, 2011), and personal reports by philosophers (see Section 1).

\subsection{Lack of gradients}

When assessing participants' WTD against left- or right-leaning individuals and viewpoints, we did not provide the three gradients 'somewhat left- or right-leaning,' 'left- or right-leaning,' and 'very left- or right-leaning,' but only used 'left- or right-leaning.' This is a limitation because the responses do not allow us to tell whether participants would act differently toward 'somewhat left- or right-leaning' versus 'very left- or right-leaning' individuals, and it might be that some interpreted our questions as referring to 'very' left- or right-leaning individuals, whereas others took them to refer only to 'somewhat' left- or right-leaning individuals.

However, in the relevant place in the survey, we did remind participants that the questions at issue referred to the middle position of each ideology only. Moreover, even if some participants interpreted them as referring to extreme positions while others interpreted them as referring to moderate ones, our results are still interesting. In the absence of any ideological bias, each participant should apply the same (extreme or moderate) reading of the gradients to both left-leaning and right-leaning individuals alike, treating them both equally negatively or positively; however, this is not what we found.

\subsection{Ambiguous concepts}

Another criticism of the survey might be that the terms (politically) 'left' and 'right' are too vague, and their meanings differ too much internationally, making the informativeness of the survey results doubtful. If the origin point of the moderate position varies across individuals or groups, then the responses will not be commensurable.

We grant that the relative vagueness of 'left' and 'right' is a limitation of our survey, but the results remain informative and important because, as we noted earlier (Section 2.1), there is a significant overlap in the meaning of the terms internationally, which has been independently confirmed by empirical research in political psychology (Caprara \& Vecchione, 2018; Noel \& Therien, 2008). This overlap ensures that the results are informative, even if not every respondent interprets the intervals we used in exactly the same 
way. ${ }^{40}$ Also, our sample was mostly European (67\%) and in countries across Europe and the EU, political structures and concepts are similar, providing an additional reason to doubt that there was a significant divergence in the understanding of the left-vs.-right distinction in most of the sample. The informative value of the survey is further supported by the overall coherence of our key results with the results of related studies using the Democrat versus Republican or liberal versus conservative distinctions (Honeycutt \& Freberg, 2017; Yancey, 2011). More generally, while a detailed investigation of the regional differences in ideological leanings and biases, as well as an investigation of philosophers' views on specific policy issues would be an interesting complement to our study, the phenomenon of ideological diversity is, just as ideology itself, a multi-dimensional phenomenon that is usefully explored by pursuing a variety of methods, including the approach we adopted here, that deploys a standard tool from the political sciences (i.e., the left-right spectrum; Caprara \& Vecchione, 2018). ${ }^{41}$

\section{Conclusion}

The survey we conducted suggests that the field of philosophy is heavily ideologically skewed toward the left, and both right-leaning individuals and moderates are underrepresented. The data we gathered also suggest that participants from across the political spectrum sometimes experience ideological bias and hostility in the field, and, occasionally, this comes from their own side of the political spectrum. In fact, a significant minority in the survey exhibited an explicit willingness to discriminate against individuals with the opposite ideology, while about half of the participants indicated that discrimination against left- or right-leaning individuals is not justified. These findings add new insights to the social psychological research on ideology and have implications for philosophers interested in meta-philosophical, ethical, and epistemological questions. This is because the data are relevant for settling whether judgment- and decision-making in philosophy are as reliable and morally responsible as they should be. The specific distribution of political viewpoints and the bias and hostility against them cast doubts on the reliability of judgment- and decision-making, because they indicate strong limitations on the scope of social criticism in the field. Moreover, they are at odds with tolerance and open dialogue. It thus seems to us that the results of this study provide reasons for concern, no matter where one stands on the political spectrum.

\section{Notes}

1. While the term 'ideology' is often used in an evaluative sense imputing to a system of beliefs some negative characteristic(s), we use it in a non-evaluative way as referring 
simply to political convictions, i.e., political "beliefs about the proper order of society and how it can be achieved" (Erikson \& Tedin, 2003, p. 64). This neutral notion is prevalent in social psychology and political science (Jost et al., 2009).

2. Neither here nor in these studies is it assumed that the underrepresentation at issue is caused solely or mostly by bias. The causal connections are complex: self-selection and other factors might be the main reasons for a group's underrepresentation. However, if there is a bias against a group, then it is not unreasonable to assume that it is likely to contribute to that underrepresentation.

3. Members of the field of philosophy - in other words, those whom we consider as 'philosophers' - include faculty, researchers, and students.

4. https://blog.apaonline.org/2018/03/26/tell-us-how-to-fix-the-lack-of-diversity-in-phi losophy-journals/.

5. See https://philosophy.stanford.edu/about/diversity-and-climate.

6. https://www.apaonline.org/page/nondiscrimination.

7. Since using the words 'bias,' 'hostility,' or 'discriminatio' to refer to, say, racists or Nazis might come problematically close to expressing sympathy with such individuals (and may amount to what Saul (2017) calls using "fig leaves"), we wish to explicitly allow for some positive, justified instances of ideological bias, hostility, and discrimination (the case just mentioned being one of them).

8. Many thanks to Lawrence Lengbeyer for prompting us to be clearer about the details of the study. The clarification that Yancey's participants were asked about their own support for the job applicant should also have been added to Peters (2019, p. 400).

9. http://dailynous.com/2016/08/30/ideas-students-protected-from-faculty-fearful-todefend/.

10. http://dailynous.com/2016/09/06/ideas-faculty-scared-defend-follow/.

11. Student protests against certain invited speakers or lecturers might also suggest some (possibly not discipline-specific) ideological hostility. For an incident involving Peter Singer at the University of Victoria (Canada), see http://www.martlet.ca/protesterscrash-effective-altruism-debate/; for a recent case involving Jeff McMahan (and a critical discussion of "no-platforming"), see McMahan (2019); for an incident involving philosophy classes on abortion, see http://dailynous.com/2017/03/31/universitysuspends-philosopher-lesson-abortion/.

12. https://www.liverpool.ac.uk/philosophy/philos-1/.

13. See our OSF platform here: https://osf.io/qd5fy/?view_only= aced37bbef6b44478c2f744920423187.

14. Nine hypotheses were pre-registered in total. For all of them and the respective findings, see https://osf.io/qd5fy/?view_only=aced37bbef6b44478c2f744920423187

15. Previous surveys on political diversity in academia were criticized for only tracking participants' responses to one particular ideology without also assessing responses to the opposite one (Skitka, 2012). Our instrument avoids this.

16. https://osf.io/qd5fy/?view_only=aced37bbef6b44478c2f744920423187.

17. Participants were excluded if they did not agree to the informed consent, or if they answered less than $50 \%$ of the questions.

18. For all questions, see https://osf.io/qd5fy/?view_only= aced37bbef6b44478c2f744920423187.

19. Participants were asked about their "colleagues in the field." We did not specify the term further, but on a natural reading, it designates individuals with whom one typically interacts when doing philosophy in academia, that is, one's departmental coworkers, including faculty members but also fellow students, postdocs, and so on. 
We acknowledge that it might not always be easy to average over one's colleagues' attitudes.

20. Since there was no mention of the quality of, say, the argument supporting the perspective in the grant application or paper, or of the possibly poorer competence of the candidate, the answers to these questions reveal a readiness to discriminate that is based primarily on ideological preference.

21. This is in line with other studies that have found a "lone moderate effect," which emerges when subjects view themselves as the only moderates in a controversy, even within their own ideological group (see Keltner \& Robinson, 1993).

22. For each variable, scores were merged such that, for example, the WTD against the 'opposition to hiring' variable was comprised of the left's scores for WTD against a right-leaning hire, as well as the right's scores for WTD against a left-leaning hire. The same was done for the other three variables. After creating the variables, a "Hotelling's Trace" analysis was conducted, $T^{2}=3.63, F(4,663)=601.63, p<.001$. It indicated that the population means for the four variables were not equal, thereby allowing us to proceed with additional analyses.

23. Chi-square analyses (recoding WTD for the four variables into dichotomous variables with $<3=$ not WTD, 3-5 = WTD) corroborated these findings: Chi-square tests of goodness of fit to determine whether WTD for left- and right-leaning participants was equivalent across the four dimensions (grant,' 'paper,' 'symposia,' hiring) revealed that WTD for left- versus right-leaning participants was not equivalent for grants, $X^{2}$ $(1, N=670)=33.58, p<.001$; for papers, $X^{2}(1, N=671)=103.08, p<.001$; for symposia, $X^{2}(1, N=670)=70.93, p<.001$; or for hiring, $X^{2}(1, N=670)=4.68$, $p=.031$.

24. Two of the authors independently classified the responses and afterward crosschecked their classifications.

25. See the Supplementary Data PHILOS-L Survey file here: https://osf.io/qd5fy/?view_ only=aced37bbef6b44478c2f744920423187.

26. Since feminist views, environmental concerns, and concerns about animal welfare are usually seen as part of a left-leaning orientation, we included responses related to them in this group.

27. The numbers in the brackets refer to the list of responses in the Supplementary Data PHILOS-L Survey file.

28. See, e.g., the websites of the Department of Philosophy at NYU (http://as.nyu.edu/ philosophy/climate.html) or of Rutgers University (https://philosophy.rutgers.edu/ about-us/discourse).

29. https://www.apaonline.org/page/nondiscrimination.

30. A reviewer notes that, for instance, subjects' radically right-leaning beliefs may lead them to make utterances about individuals (e.g., women, members of ethnic minorities, etc.) that do not just express the beliefs but also indirectly address the individuals concerned. This interlocutory dimension of the expressions creates harm, and it may be that the envisaging of this harm is what drove the discriminatory responses in some of our participants. We agree that it is important to acknowledge and further analyze this interlocutory dimension of the expression of ideological beliefs in order to arrive at an adequate account of the justificatory basis of the discrimination we tracked.

31. Thanks to James Robert Brown for prompting us to be more specific about our claims. See also footnote 7 .

32. For a more detailed argument for this view, see Peters (2019, p. 403). 
33. https://www.phil.cam.ac.uk/prosp-students/copy2_of_GraduateProspectus1920_ FINAL.pdf/at_download/file.

34. https://edu.admin.ox.ac.uk/home.

35. http://as.nyu.edu/philosophy/climate.html.

36. https://philosophy.rutgers.edu/about-us/discourse.

37. https://www.apaonline.org/page/codeofconduct; see also the American Philosophical Association "rejects as unethical all forms of discrimination based on ... political convictions" (https://www.apaonline.org/page/nondiscrimination).

38. The low response rate might have been due to the fact that the survey was sent out in June and July of 2018, which is when many faculties are occupied with end-ofterm activities, marking, and so on. Notice too that many subscribers to PHILOS$\mathrm{L}$ are administrative staff and as such will not respond to surveys of the kind at issue.

39. While our sample consisted of $43,2 \%$ students and $49.7 \%$ faculty members, even if most participants had been students, our findings would still be valuable in revealing insights into the ideological climate for students in the field.

40. The referents of political 'left' and 'right' that participants in international surveys are likely to have in mind might be construed as Wittgensteinian "family resemblance" concepts. See Cochrane (2015) for a development of this idea which is congenial to our view here.

41. The policy- or issue-based elements of ideology are distinct from its social-identity elements, which are broader and need to be explored separately (Mason, 2018).

\section{Acknowledgments}

This research was partially supported by the Research Council of KU Leuven, grant agreement $\mathrm{n}^{\circ} 3 \mathrm{H} 160214$. For very helpful comments on earlier drafts of the paper, we would like to thank Alex Krauss, Jenny Saul, Edouard Machery, Albert Newen, and Thomas W. Simpson. For interesting discussions on the topic, survey design, and data analysis, many thanks to Lorenz Demey, Massimiliano Simons, Leander Vignero, Jan Heylen, and Olivier Lemeire. Many thanks also to Kirk Ludwig and Justin Weinberg for critical feedback on the survey.

\section{Disclosure Statement}

No potential conflict of interest was reported by the authors.

\section{Funding}

This work was supported by the Research Council of KU Leuven [grant agreement $\mathrm{n}^{\circ}$ 3H160214].

\section{ORCID}

Nathan Honeycutt (D) http://orcid.org/0000-0002-6529-130X 


\section{References}

Allen-Hermanson, S. (2017a). Leaky pipeline myths: In search of gender effects on the job market and early career publishing in philosophy. Frontiers in Psychology, 8(953), 1-10. https://doi.org/10.3389/fpsyg.2017.00953

Allen-Hermanson, S. (2017b). Implicit bias, stereotype threat, and political correctness in. Philosophy Philosophies, 2(2), 12. https://doi.org/10.3390/philosophies2020012

Antony, L. (2016). Bias: Friend or foe? Reflections of Saulish skepticism. In M. Brownstein \& J. Saul (Eds.), Implicit bias and philosophy, volume 1: Metaphysics and epistemology (pp. 157-190). OUP.

Arneson, R. (2015). Liberalism and Equality. In S. Wall (Ed.), Cambridge companion to liberalism (pp. 212-236). CUP.

Bar Tal, D. (2017). Self-Censorship as a socio-political-psychological phenomenon: Conception and research. Political Psychology, 38(S1), 37-65. https://doi.org/10.1111/ pops.12391

Bobbio, N. (1996). Left and right: The significance of a political distinction. University of Chicago Press.

Botts, T., Bright, L., Cherry, M., Mallarangeng, G., \& Spencer, Q. (2014). What is the state of blacks in philosophy? Critical Philosophy of Race, 22 2), 224-242. Project MUSE, muse.jhu. edu/article/552772 https://doi.org/10.5325/critphilrace.2.2.0224

Bourget, D., \& Chalmers, D. (2014). What do philosophers believe? Philosophical Studies, 170(3), 465-500. https://doi.org/10.1007/s11098-013-0259-7

Brandt, M. J., Reyna, C., Chambers, J. R., Crawford, J. T., \& Wetherell, G. (2014). The ideological-conflict hypothesis: Intolerance among both liberals and conservatives. Current Directions in Psychological Science, 23(1), 27-34. https://doi.org/10.1177/ 0963721413510932

Brownstein, M., \& Saul, J. (2016). Implicit bias and philosophy. OUP.

Caprara, G. V., \& Vecchione, M. (2018). On the left and right ideological divide: Historical accounts and contemporary perspectives. Political Psychology, 39, 49-83. https://doi.org/ 10.1111/pops.2018.39.issue-S1

Carl, N. (2015). Does intelligence have a U-shaped relationship with leftism? Intelligence, 49, 159-170. https://doi.org/10.1016/j.intell.2015.01.008

Case, S. (2015). Political bias in philosophy and why it matters. National Association of Scholars. URL https://www.nas.org/articles/political_bias_in_philosophy_and_why_it_ matters

Cochrane, C. (2015). Left and right: The small world of political ideas. McGill-Queen's University Press.

Cohen, G. A. (2006). Are freedom and equality compatible? In R. Goodin \& P. Pettit (Eds.), Contemporary political philosophy: An anthology (pp. 416-425). Blackwell Publishing.

Crawford, J. T., Brandt, M. J., Inbar, Y., Chambers, J. R., \& Motyl, M. (2017). Social and economic ideologies differentially predict prejudice across the political spectrum, but social issues are most divisive. Journal of Personality and Social Psychology, 112(3), 383412. https://doi.org/10.1037/pspa0000074

Draper, P., Nichols, R., \& Sugden, S. J. B. (2013). Diagnosing bias in philosophy of religion. The Monist, 96(3), 420-446. https://doi.org/10.5840/monist201396319

Duarte, J., Crawford, J., Stern, C., Haidt, J., Jussim, L., \& Tetlock, P. (2015). Political diversity will improve social psychological science. Behavioral and Brain Sciences, 38, 1-13. https:// doi.org/10.1017/S0140525X14000430

Erikson, R., \& Tedin, K. (2003). American public opinion. Longman. 
Fantl, J. (2018). The limitations of the open mind. OUP.

Gampa, A., Wojcik, S., Motyl, M., Nosek, B. A., \& Ditto, P. (2019). (Ideo)logical reasoning: Ideology impairs sound reasoning. Social Psychological and Personality Science, 1-9. https://doi.org/10.1177/1948550619829059

Goldfarb, M. (2010). Liberal? Are we talking about the same thing? BBC News. URL https:// www.bbc.com/news/world-10658070

Haslanger, S. (2008). Changing the ideology and culture of philosophy: Not by reason (Alone). Hypatia, 23(2), 210-223. https://doi.org/10.1111/j.1527-2001.2008.tb01195.x

Heywood, A. (2015). Key concepts in politics and international relations. Palgrave Macmillan.

Hicks, D. (2011). Is Longino's conception of objectivity feminist? Hypatia, 26(2), 333-351. https://doi.org/10.1111/j.1527-2001.2010.01160.x

Hidalgo, J., \& Freiman, C. (2016). Liberalism or immigration restrictions, but not both. Journal of Ethics and Social Philosophy, 10(2), 1-22.

Holbrook, A., Krosnick, J., \& Pfent, A. (2007). The causes and consequences of response rates in surveys by the news media and government contractor survey research firms. In J. M. Lepkowski, N. C. Tucker, J. M. Brick, E. D. De Leeuw, L. Japec, P. J. Lavrakas, et al (Eds.), Advances in telephone survey methodology. Wiley.

Honeycutt, N., \& Freberg, L. (2017). The liberal and conservative experience across academic disciplines. Social Psychological and Personality Science, 8(2), 115-123. https://doi. org/10.1177/1948550616667617

Inbar, Y., \& Lammers, J. (2012). Political diversity in social and personality psychology. Perspectives on Psychological Science, 7(5), 496-503. https://doi.org/10.1177/ 1745691612448792

Iyengar, S., \& Massey, D. S. (2019). Scientific communication in a post-truth society. Proceedings of the National Academy of Sciences, 116(16), 7656-7661. https://doi.org/10. 1073/pnas.1805868115

Iyengar, S., \& Westwood, S. (2015). Fear and loathing across party lines: New evidence on group polarisation. American Journal of Political Science, 59(3), 690-707. https://doi.org/ 10.1111/ajps. 12152

Jost, J., Federico, C., \& Napier, J. (2009). Political ideology: Its structure, functions, and elective affinities. Annual Review of Psychology, 60(1), 307-337. https://doi.org/10.1146/ annurev.psych.60.110707.163600

Jussim, L., Stevens, S. T., \& Honeycutt, N. (2018). Unasked questions about stereotype accuracy. Archives of Scientific Psychology, 6(1), 214-229. https://doi.org/10.1037/ $\operatorname{arc0000055}$

Keltner, D., \& Robinson, R. J. (1993). Imagined ideological differences in conflict escalation and resolution. International Journal of Conflict Management, 4(3), 249-262. https://doi. org/10.1108/eb022728

Kidd, I. J. (2017). Resisters, diversity in philosophy, and the demographic problem. Rivista di estetica, 64(64), 118-134. https://doi.org/10.4000/estetica

Kings, A. M. (2019). Philosophy's diversity problem. Metaphilosophy, 50(3), 212-230. https://doi.org/10.1111/meta.12358

Klein, D., \& Stern, C. (2009). By the numbers: The ideological profile of professors. In R. Maranto, R. Redding, \& F. Hess (Eds.), The politically correct university: Problems, scope, and reforms (pp. 15-38). AEI Press.

Knobe, J., \& Nichols, S. (2017). Experimental philosophy. The stanford encyclopedia of philosophy. (Winter 2017 Edition). E. N. Zalta (ed.), URL https://plato.stanford.edu/ archives/win2017/entries/experimental-philosophy/ 
Koch, A, Imhoff, R, Dotsch, R, Unkelbach, C, \& Alves, H. (2016). The abc of stereotypes about groups: agency/socioeconomic success, conservative-progressive beliefs, and communion. Journal Of Personality and Social Psychology, 110, 675-709.

Kornblith, H. (1999). Distrusting reason. Midwest Studies in Philosophy, 23(1), 181-196. https://doi.org/10.1111/1475-4975.00010

Kourany, J. (2016). Should some knowledge be forbidden? The case of cognitive differences research. Philosophy of Science, 83(5), 779-790. https://doi.org/10.1086/687863

Longino, H. (2002). Science as social knowledge: Values and objectivity in scientific inquiry. Princeton University Press.

Lukes, S. (2003). Epilogue: The grand dichotomy of the twentieth century. In T. Ball \& R. Bellamy (Eds.), The Cambridge history of twentieth-century political thought (pp. 602626). Cambridge University Press.

Maher, P. J., Igou, E. R., \& van Tilburg, W. A. P. (2018). Brexit, Trump, and the Polarizing effect of disillusionment. Social Psychological and Personality Science, 9(2), 205-213. https://doi.org/10.1177/1948550617750737

Mair, P. (2009). Left-right orientations. In R. J. Dalton \& H. D. Klingemann (Eds.), The Oxford handbook of political behavior. OUP.

Maroja, L. (2019). Self-censorship on campus is bad for science. The Atlantic. URL https:// www.theatlantic.com/ideas/archive/2019/05/self-censorship-campus-bad-science/ $589969 /$

Mason, L. (2018). Ideologues without issues: the polarizing consequences of ideological identities. Public Opinion Quarterly, 82(S1), 280-301. doi:10.1093/poq/nfy005

McLachlan, H. (1977). Must we accept either the conservative or the liberal view on abortion? Analysis, 37(4), 197-204. https://doi.org/10.1093/analys/37.4.197

McMahan, J. (2019). I was no-platformed. Here's why it's counterproductive. NewStatesman. URL https://www.newstatesman.com/2019/01/i-was-no-platformedhere-s-why-it-s-counterproductive

Morton, S., Bandara, D., \& Robinson, E. (2012). In the 21st century, what is an acceptable response rate? Australian and New Zealand Journal of Public Health, 36(2), 106, 8. https:// doi.org/10.1111/j.1753-6405.2012.00854.x

Noel, A., \& Therien, J. (2008). Left and right in global politics. CUP.

Paxton, M., Figdor, C., \& Tiberius, V. (2012). Quantifying the gender gap: An empirical study of the underrepresentation of women in philosophy. Hypatia, 27(4), 949-957. https://doi.org/10.1111/hypa.2012.27.issue-4

Peters, U. (2019). Implicit bias, ideological bias, and epistemic risks in philosophy. Mind \& Language, 34(3), 393-419. https://doi.org/10.1111/mila.2019.34.issue-3

Peters, U. (forthcoming). Illegitimate values, confirmation bias, and mandevillian cognition in science. British Journal for Philosophy of Science.

Popper, K. (1945). The open society and its enemies. Routledge.

Priest, G. (2006). What is philosophy? Philosophy, 81(2), 189-207. https://doi.org/10.1017/ S0031819106316026

Rajczi, A. (2014). What is the conservative point of view about distributive justice? Public Affairs Quarterly, 28(4), 341-373.

Rawls, J. (1971). A theory of justice. Harvard University Press.

Richardson, S. (2010). Feminist philosophy of science: History, contributions and challenges. Synthese, 177(3), 337-362. https://doi.org/10.1007/s11229-010-9791-6

Riggs, W. (2010). Open-mindedness. Metaphilosophy, 41(1/2), 172-188. https://doi.org/10. 1111/j.1467-9973.2009.01625.x 
Rockey, J. (2014). Who is left-wing and who just thinks they are? University of Leicester Working Paper No. 09/23. URL https://www.le.ac.uk/ec/research/RePEc/lec/leecon/dp0923.pdf

Rolin, K. (2002). Gender and trust in science. Hypatia, 17(4), 95-118. https://doi.org/10. 1111/hypa.2002.17.issue-4

Rosas, J., \& Ferreira, A. (2013). Left and right: The great dichotomy revisited. Cambridge Scholars Publishing.

Rothman, S., \& Lichter, R. (2009). The vanishing conservative: Is there a glass ceiling? In R. Maranto, R. Redding, \& F. Hess (Eds.), The politically correct university: Problems, scope, and reforms (pp. 60-76). AEI Press.

Saul, J. (2013). Skepticism and implicit bias. Disputatio, 5(37), 243-263. https://doi.org/10. 2478/disp-2013-0019

Saul, J. (2015). Let's discuss rejections of feminist philosophy. Feminist Philosophers. URL https://feministphilosophers.wordpress.com/?s=ideological+bias

Saul, J. (2017). Racial figleaves, the shifting boundaries of the permissible, and the rise of Donald Trump. Philosophical Topics, 45(2), 97-116. https://doi.org/10.5840/ philtopics 201745215

Sax, L., Gilmartin, S., \& Bryant, A. (2003). Assessing response rates and nonresponse bias in web and paper surveys. Research in Higher Education, 44(4), 409-432. https://doi.org/10. 1023/A:1024232915870

Schwitzgebel, E. (2008). Political affiliations of American Philosophers, political scientists, and other academics. The Splintered Mind. URL http://schwitzsplinters.blogspot.be/ 2008/06/political-affiliations-of-american.html

Schwitzgebel, E., \& Hassoun, N. (2018). Tell us how to fix the lack of diversity in philosophy journals. Blog of the APA. URL https://blog.apaonline.org/2018/03/26/tell-us-how-to-fixthe-lack-of-diversity-in-philosophy-journals/

Scruton, R. (2014). How to be conservative. Bloomsbury Continuum.

Sesardic, N. (2010). Nature, nurture, and politics. Biology \& Philosophy, 25(3), 433-436. https://doi.org/10.1007/s10539-009-9159-9

Sesardic, N. (2016). When reason goes on holiday: Philosophers in politics. Encounter.

Shields, J., \& Dunn, J. (2016). Passing on the right: Conservative professors in the Progressive University. OUP.

Skitka, L. J. (2012). Multifaceted problems: Liberal bias and the need for scientific rigor in self-critical research. Perspectives on Psychological Science, 7(5), 508-511. https://doi.org/ $10.1177 / 1745691612454135$

Stanley, J. (2015). How Propaganda works. Princeton University Press.

Stevens, S. T., Jussim, L., Anglin, S. M., \& Honeycutt, N. (2018). Direct and indirect influences of political ideology on perceptions of scientific findings. In B. T. Rutjens \& M. J. Brandt (Eds.), Belief systems and perceptions of reality (pp. 108-124). Routledge.

Templeton, L., Deehan, A., Taylor, C., Drummond, C., \& Strang, J. (1997). Surveying general practitioners: Does a low response rate matter? British Journal of General Practice, 47(415), 91-94.

Visser, P., Krosnick, J., Marquette, J., \& Curtin, M. (1996). Mail surveys for election forecasting? An evaluation of the Colombia dispatch poll. Public Opinion Quarterly, 60 (2), 181-227. https://doi.org/10.1086/297748

Walzer, M. (1997). On Toleration. Yale University Press.

Weinberg, J. (2016). Which ideas are students protected from? Which are faculty fearful to defend? Daily Nous. http://dailynous.com/2016/08/30/ideas-studentsprotected-fromfaculty-fearful-to-defend/ 
Westwood, J. S., Iyengar, S., Walgrave, S., Leonisio, R., Strijbis, O., \& Miller, L. (2018). The tie that divides: Cross-national evidence of the primacy of partyism. European Journal of Political Research, 57(2), 333-354. https://doi.org/10.1111/ejpr.2018.57.issue-2

Yancey, G. (2011). Compromising scholarship: Religious and political bias in American Higher Education. Baylor University Press. 